Controlling Inflation in a Cointegrated Vector Autoregressive Model with an Application to US Data

Juselius, Katarina; Johansen, Søren

Publication date:

2001

Document version

Early version, also known as pre-print

Citation for published version (APA):

Juselius, K., \& Johansen, S. (2001). Controlling Inflation in a Cointegrated Vector Autoregressive Model with an Application to US Data. Department of Economics, University of Copenhagen. 


\section{DISCUSSION PAPERS Department of Economics University of Copenhagen}

\section{1-03}

Controlling Inflation in a Cointegrated Vector Autoregressive Model with an Application to US Data

Søren Johansen Katarina J uselius

Studiestræde 6, DK-1455 Copenhagen K., Denmark Tel. +45 35323082 - Fax +45 35323000 http://www.econ.ku.dk 


\title{
Controlling inflation in a cointegrated vector autoregressive model with an application to US data.
}

\author{
Søren Johansen and Katarina Juselius \\ Economics Department, European University Institute, \\ Florence
}

January 2001

\begin{abstract}
The notions of instrument, intermediate target and final target are defined in the context of the cointegrated VAR. A target variable is said to be controllable if it can be made stationary around a desired target value by using the instrument. This can be expressed as a condition on the long-run impact matrix. Applying a control rule to intervene in the market changes the dynamics of the process and the properties of the new controlled process have to be derived. The theoretical results are applied to US monetary data on a daily and monthly basis. The empirical results do not provide support for the widely held belief that the Federal Reserve Bank can bring US CPI inflation down by increasing the federal funds rate.

Keywords: Inflation Target, Monetary Instruments, Control Rules

JEL Classification: C3, E5
\end{abstract}


Table 1: Elements of monetary policy

\begin{tabular}{lllll}
\hline Instruments: & Intermediate Targets & Final Targets \\
\hline - Reserve requirements & & • Money Stock & $\rightarrow$ & ・ Inflation Rate \\
$\begin{array}{l}\text { on private banks } \\
\text { - Central bank interest }\end{array}$ & & & & \\
$\begin{array}{l}\text { rates } \\
\text { - Open market operations }\end{array}$ & & • Market Interest & $\rightarrow$ & $\bullet$ GDP Growth \\
$\begin{array}{l}\text { - Interventions in the } \\
\text { foreign currency market }\end{array}$ & $\rightarrow$ & $\bullet$ Exchange rates & $\rightarrow$ & $\bullet$ Purchasing \\
\hline
\end{tabular}

\section{Introduction}

Monetary policy reaction rules have recently obtained a lot of attention. The original idea, first suggested by Taylor (1993), was to describe a central bank's policy decisions by a simple rule that associated changes in the monetary instrument with the discrepancy between the target variable and its desired value and with the state of the economy summarized by some key macroeconomic variables. Further developments have included different models and approaches (forward looking rational expectations versus adaptive expectations, micro foundations versus no such foundations), see for example the collected papers in Taylor (1999), Clarida, Gali and Gertler (1998) and references therein. Most of the applications contain the following elements: a formulation of a monetary policy rule for the central bank, estimation of a model for the economy (usually a VAR), derivations of the implications of the proposed rule, and finally an investigation if monetary authorities have followed the suggested rule. In general, the papers do not ask under which conditions the ultimate targets, or the goal variables, can be controlled given the instruments and the mechanisms of the economy. This is the purpose of the present paper.

The diagram in Table 1 illustrates the relation between monetary instruments, intermediate and final targets (or goals). The central bank changes the instruments in order to influence the goal variables via some intermediate targets. For example, a central banker may change the reserve requirements of the private banks (quantity control) to influence the level of money stock in the economy, under the assumption that $(i)$ there is a direct relationship between the level of money stock and the price level and (ii) the level of causation goes from money stock to prices. Alternatively, a central banker may change the discount rate (direct price control) or engage in open market operations (indirect price control) under the assumption that this will influence the market interest rates, and eventually aggregate demand (GDP growth) and money demand (money stock).

In practice the time it takes for a policy intervention to influence the final target has generally been found to be long and difficult to predict, whereas the response of an intermediate target is more immediate and, therefore, easier to 
estimate empirically. Moreover, the interventions take place on a daily basis, but the inflation rate, the target variable, is only measured on a monthly basis. Hence, the direct evaluation of the final impact of a monetary intervention on the goal variable is often difficult. Because of this the assessment of monetary policy has often been based on models containing intermediate targets and goal variables, but not necessarily the instrument variables. The paper demonstrates that this can still be a valid procedure if the intermediate target can be controlled by the central bank authorities and if it cointegrates with the final target.

The empirical application, which is based on US data, approaches the empirical assessment of the policy control problem in two levels: In the first step we examine whether the Federal Reserve Bank is able to control the short-term market rate (here the 3 months tbill rate) using the federal funds rate as an instrument. In the second step we examine whether the tbill rate can be considered an appropriate intermediate target, defined as being cointegrated with non-zero coefficients with the final target, the inflation rate.

A basic assumption here is that the VAR model is capable of satisfactorily describing the dynamics of the data and that the equations for the variables that are not subject to intervention remain the same before as after the intervention. In such a model we say that a target variable is controllable if it can be made stationary around a given mean. Thus, for a nonstationary target variable we want to achieve both stationarity and the desired mean.

For ease of exposition, the general theory for applying a linear control rule is given in the Appendix, whereas the main bulk of the paper discusses a simple rule that appears natural for the cointegrated VAR models we consider here.

The control problem is formulated in Section 2: A formal definition of an instrument, an intermediate target, and a final target is given and a natural control rule is formulated that exploits the dynamics of the VAR process. Section 3 derives the properties of the controlled process, i.e. the process that arises as a consequence of applying the derived control rule all the time.

The empirical illustration is discussed in Sections 4 and 5. The condition for controllability of an intermediate target is checked in Section 4 using daily observations of the US federal target rate, the federal funds rate and the 3 and 6 months treasury bill rates. Section 5 investigates whether the Federal Reserve Bank can control the inflation rate, given the estimated relationship between the instruments and the intermediate targets and the transmission mechanism of the macroeconomy. The latter is described by a VAR of real money, output, inflation rate, the 10 years bond rate, the 3 and 6 months treasury bill rates, the federal funds rate, and the federal target rate. Section 6 concludes. In Appendix A the results on the general linear control rule are given and Appendix B contains various graphs of the data. 


\section{Definition of the control problem}

We assume that the transmission mechanism of the economy can be described by the cointegrated $\operatorname{VAR}(\mathrm{k})$ model given in the error correction form:

$$
\Delta x_{t}-\gamma=\alpha\left(\beta^{\prime} x_{t-1}-\rho^{\prime}(t-1)-\mu\right)+\sum_{i=1}^{k-1} \Gamma_{i}\left(\Delta x_{t-i}-\gamma\right)+\varepsilon_{t}, t=1, \ldots, T,
$$

where $x_{t}$ is $p$-dimensional, $\alpha$ and $\beta$ are $p \times r$ of $\operatorname{rank} r, \Gamma_{i}$ is $p \times p, \gamma$ is $p \times 1$ and $\rho^{\prime}=\beta^{\prime} \gamma$. The errors are i.i.d. with mean zero and variance $\Omega$.

To simplify notation in this section the basic definitions are introduced for the cointegrated $\operatorname{VAR}(1)$ model without trend, i.e. for $\Gamma_{i}=0$ for all $i, \gamma=0$. The equation (1) then becomes

$$
\Delta x_{t}=\alpha\left(\beta^{\prime} x_{t-1}-\mu\right)+\varepsilon_{t},
$$

which defines a cointegrated $I(1)$ process if and only if the parameters satisfy the restriction

$$
\left|e i g\left(I_{r}+\beta^{\prime} \alpha\right)\right|<1,
$$

that is, the eigenvalues of $I_{r}+\beta^{\prime} \alpha$ have absolute value less than one. In this case the process is represented as

$$
x_{t}=C \sum_{i=1}^{t} \varepsilon_{i}+y_{t}+A+\alpha\left(\beta^{\prime} \alpha\right)^{-1} \mu,
$$

where $A$ depends on initial values $\left(\beta^{\prime} A=0\right), y_{t}$ is stationary with mean zero and hence $\beta^{\prime} x_{t}=\beta^{\prime} y_{t}+\mu$ is stationary with mean $\mu$, and the long-run impact matrix is

$$
C=\beta_{\perp}\left(\alpha_{\perp}^{\prime} \beta_{\perp}\right)^{-1} \alpha_{\perp}^{\prime}=I_{p}-\alpha\left(\beta^{\prime} \alpha\right)^{-1} \beta^{\prime},
$$

where $\alpha_{\perp}$ is a $p \times(p-r)$ matrix of full rank, so that $\alpha^{\prime} \alpha_{\perp}=0$. If $\alpha=0$ (so that there is no equilibrium error correction) then $\alpha_{\perp}=I_{p}$ (i.e. $p$ autonomous stochastic trends in the data), and if $\alpha=I_{p}$ (i.e. $x_{t} \sim I(0)$ ) then $\alpha_{\perp}=0$ (no stochastic trends in the data). Condition (3) implies that $\beta^{\prime} \alpha$ has full rank, and this is equivalent to $\left|\alpha_{\perp}^{\prime} \beta_{\perp}\right| \neq 0$, so that $C$ is well defined. Since $\beta^{\prime} x_{t}$ is a $\operatorname{VAR}(1)$ process with coefficient matrix $\left(I_{r}+\beta^{\prime} \alpha\right)$, the condition for stationarity (3) rules out unit roots and explosive roots, see Johansen (1996, Theorem 4.2) for proofs. We define the attractor set by

$$
\left\{x \mid \beta^{\prime} x=\mu\right\}=\alpha\left(\beta^{\prime} \alpha\right)^{-1} \mu+s p\left(\beta_{\perp}\right) .
$$

Figure 1 illustrates the adjustment dynamics of the process, which for the simple $\operatorname{VAR}(1)$ are given by the vectors $\pm \alpha$. Since they point towards the attractor set, the process is pulled towards the latter with a force that depends on 


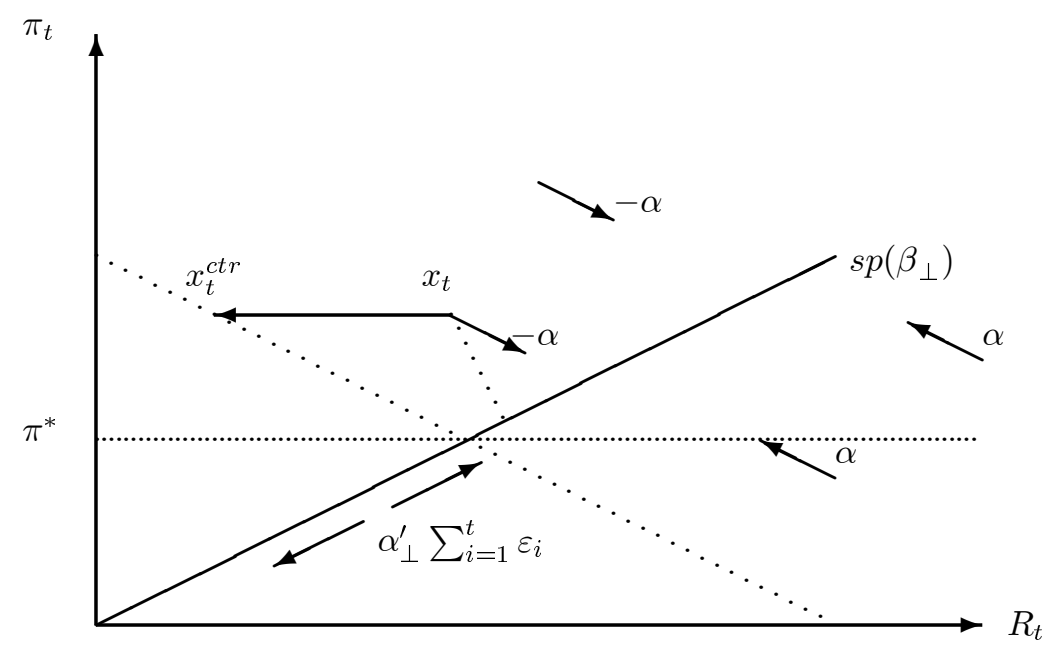

Figure 1: At the point $x_{t}=\left(R_{t}, \pi_{t}\right)$ the process is moved to $x_{t}^{c t r}$ by changing the nominal interest rate $R_{t}$. If the errors were switched off, the process would move from this position along the direction of $-\alpha$ to a point where inflation $\pi_{t}=\pi^{*}$.

the magnitude of the distance $\beta^{\prime} x_{t}-\mu$. Thus, for points on the attractor set the force is zero and there is no tendency to move away, and such points are called equilibrium points or steady state points. The common trends $\alpha_{\perp}^{\prime} \sum_{i=1}^{t} \varepsilon_{i}$ push the process along the attractor set and generate the nonstationary behavior of the process.

The solution of (2) with initial value $x_{0}$ can also be written as

$$
x_{t}=\left(I_{n}+\alpha \beta^{\prime}\right)^{t} x_{0}+\sum_{i=0}^{t-1}\left(I_{n}+\alpha \beta^{\prime}\right)^{i}\left(\varepsilon_{t-i}-\alpha \mu\right) .
$$

The following result is based on (6):

Lemma 1 For the $I(1)$ process $x_{t}$ given by (2) the expectation $E\left(x_{t} \mid x_{0}\right)$ converges to

$$
x_{\infty}=\lim _{t \rightarrow \infty} E\left(x_{t} \mid x_{0}\right)=C x_{0}+\alpha\left(\beta^{\prime} \alpha\right)^{-1} \mu,
$$

the long-run expected value, which is a point in the attractor set.

Proof. From the relations

$$
\alpha_{\perp}^{\prime}\left(I_{p}+\alpha \beta^{\prime}\right)^{t}=\alpha_{\perp}^{\prime} \text { and } \beta^{\prime}\left(I_{p}+\alpha \beta^{\prime}\right)^{t}=\left(I_{r}+\beta^{\prime} \alpha\right)^{t} \beta^{\prime}
$$


it follows from (6) that

$$
\begin{aligned}
E\left(\alpha_{\perp}^{\prime} x_{t} \mid x_{0}\right) & =\alpha_{\perp}^{\prime} x_{0}, \\
E\left(\beta^{\prime} x_{t} \mid x_{0}\right) & =\left(I_{r}+\beta^{\prime} \alpha\right)^{t} \beta^{\prime} x_{0}-\sum_{i=0}^{t-1}\left(I_{r}+\beta^{\prime} \alpha\right)^{i} \beta^{\prime} \alpha \mu \\
& \rightarrow-\sum_{i=0}^{\infty}\left(I_{r}+\beta^{\prime} \alpha\right)^{i} \beta^{\prime} \alpha \mu=\mu .
\end{aligned}
$$

Hence, using (4) we find

$$
E\left(x_{t} \mid x_{0}\right)=\beta_{\perp}\left(\alpha_{\perp}^{\prime} \beta_{\perp}\right)^{-1} E\left(\alpha_{\perp}^{\prime} x_{t} \mid x_{0}\right)+\alpha\left(\beta^{\prime} \alpha\right)^{-1} E\left(\beta^{\prime} x_{t} \mid x_{0}\right) \rightarrow C x_{0}+\alpha\left(\beta^{\prime} \alpha\right)^{-1} \mu .
$$

Because $\beta^{\prime} x_{\infty}=\beta^{\prime}\left(C x_{0}+\alpha\left(\beta^{\prime} \alpha\right)^{-1} \mu\right)=\mu$, it follows that $x_{\infty}$ is in the attractor set (5), i.e. is an equilibrium, or steady state point. We say that the position $x_{0}$ aims at the long-run expectation $x_{\infty}$. See also Proietti (1997), Bruneau and Jondeau (1999), and Bedini and Mosconi (2000).

The following definitions are needed for the discussion of control theory in terms of instruments, intermediate and ultimate targets:

Definition 2 (i) Instrument variables $a^{\prime} x_{t},(a(p \times m))$ have the property that we can change them by an intervention, so that the value $a^{\prime} x_{t}$ is replaced by $a^{\prime} x_{t}+v$, for any $v \in R^{m}$.

(ii) Final or ultimate target variables $b^{\prime} x_{t},(b(p \times m))$ are the variables we would like to make stationary with mean $b^{*}$, the desired target value. The target space is given by the positions $x$ which satisfy

$$
\left\{x \mid b^{\prime} x=b^{*}\right\} .
$$

(iii) Intermediate target variables $c^{\prime} x_{t},(c(p \times m))$ are variables that are cointegrated with the final target $b^{\prime} x_{t}$, so that there exists a stationary relation $c^{\prime} x_{t}+\phi b^{\prime} x_{t}$ where the matrix $\phi(m \times m)$ has full rank.

After an intervention that changes the current value of $a^{\prime} x_{t}$ to $a^{\prime} x_{t}+v$ the controlled value of the process $x_{t}$ becomes:

$$
x_{t}^{c t r}=\bar{a}_{\perp} a_{\perp}^{\prime} x_{t}^{c t r}+\bar{a} a^{\prime} x_{t}^{c t r}=\bar{a}_{\perp} a_{\perp}^{\prime} x_{t}+\bar{a}\left(a^{\prime} x_{t}+v\right)=x_{t}+\bar{a} v,
$$

where $\bar{a}=a\left(a^{\prime} a\right)^{-1}$ and $\bar{a}_{\perp}$ is similarly defined. In practice the intervention $v$ will depend on current and lagged values of the process. It is a major assumption in this paper that if the same intervention rule is applied at all time points the equations (1) will generate a new process $x_{t}^{\text {new }}$ taking into account the interventions but otherwise leaving the parameters of the model unchanged. For a discussion of the new process see Section 3.

Definition $3 A$ set of target variables $b^{\prime} x_{t}$ with target value $b^{*}$ is controllable by the intervention $a^{\prime} x_{t}$ and the control rule $\left(\kappa, \kappa_{0}\right)$ if, by intervening at all time points using

$$
x_{t}^{c t r}=x_{t}+\bar{a}\left(\kappa^{\prime} x_{t}-\kappa_{0}\right),
$$


the new process has the property that the target, $b^{\prime} x_{t}^{\text {new }}$, becomes stationary with mean $b^{*}$.

Thus, the effect of controlling a nonstationary variable is partly to remove the nonstationarity and partly to give it the desired mean.

As a simple example consider a VAR of inflation rate, interest rate, and output gap,

$$
x_{t}^{\prime}=\left(\pi_{t}, R_{t},\left(y-y^{*}\right)_{t}\right) .
$$

The central bank wants to achieve a desired inflation rate, $\pi^{*}=2 \%$, using the interest rate as an instrument. In this case $b^{\prime}=(1,0,0), a^{\prime}=(0,1,0)$ and the positions in the target space that satisfy $b^{\prime} x_{t}=b^{*}$ are given by $\pi_{t}=2 \%$.

A simple control rule is to replace $a^{\prime} x_{t}=R_{t}$ by $R_{t}+v$, and the problem is how to choose $v=\kappa^{\prime} x_{t}-\kappa_{0}$ so that $b^{\prime} x_{t}=\pi_{t}$ becomes stationary around $2 \%$ in the new process.

In Appendix A we derive in Theorem 7 a necessary condition for making a nonstationary target variable stationary around a desired value based on a general rule $v=\kappa^{\prime} x_{t}-\kappa_{0}$. Here we focus on the derivation of a simple control rule for a set of nonstationary targets with a natural interpretation related to the dynamics of the process.

The idea, illustrated in Figure 1, is to move the process to a controlled position $x_{t}^{c t r}$ by choosing the intervention $v$ such that, if the errors were switched off, the process $x_{t+h}, h=1,2, \ldots$, starting at $x_{t}^{c t r}$, would continue towards a point in the target space. That is, we choose $v$ so that

$$
b^{*}=b^{\prime}\left(C x_{t}^{c t r}+\alpha\left(\beta^{\prime} \alpha\right)^{-1} \mu\right)=b^{\prime}\left(C\left(x_{t}+\bar{a} v\right)+\alpha\left(\beta^{\prime} \alpha\right)^{-1} \mu\right),
$$

see Lemma 1. For the equations to have a solution for $v$, the following condition

$$
\operatorname{rank}\left(b^{\prime} C a\right)=m
$$

has to be satisfied. This defines the condition for controllability, see Theorem 7 where the precise result is formulated.

If $\left|b^{\prime} C a\right| \neq 0$, equation (7) can be solved for $v$ which, using (4), gives us the control rule

$$
\begin{aligned}
\bar{a} v & =\bar{a}\left(b^{\prime} C \bar{a}\right)^{-1}\left(b^{*}-b^{\prime} \alpha\left(\beta^{\prime} \alpha\right)^{-1} \mu-b^{\prime} C x_{t}\right) \\
& =a\left(b^{\prime} C a\right)^{-1}\left[b^{*}-b^{\prime} x_{t}+b^{\prime} \alpha\left(\beta^{\prime} \alpha\right)^{-1}\left(\beta^{\prime} x_{t}-\mu\right)\right] .
\end{aligned}
$$

The intervention (9) needed to put the process on the right track depends on

- $b^{*}-b^{\prime} x_{t}$, which is the observed discrepancy between the value of the target variable $b^{\prime} x_{t}$ and its desired target value $b^{*}$,

- $\beta^{\prime} x_{t}-\mu$, which measures the deviation from steady state at the time of the intervention. 
If the economy is in steady state, as defined by the attractor set $\left\{\beta^{\prime} x=\mu\right\}$, then the discrepancy between the target and the target value determines the magnitude of the necessary intervention. But if the economy is away from steady state, then the magnitude of the steady state error also affects the size of the intervention.

Controllability is defined by a condition on the elements of the long-run impact matrix, see (4), which is defined by the orthogonal complements of $\alpha$ and $\beta$. Therefore, a stationary variable, which is a linear combination of $\beta^{\prime} x_{t}$, cannot be controlled by this rule. In the simple case of one target and one instrument, condition (8) requires that the long-run impact of a shock (an intervention) to the instrument variable on the target variable must not be zero. Therefore, controllability is inconsistent with long-run neutrality of target to instrument.

To summarize, we have seen that if $\left|b^{\prime} C a\right| \neq 0$ it is possible to define a natural control rule by

$$
x_{t}^{c t r}=x_{t}+a\left(b^{\prime} C a\right)^{-1}\left[\left(b^{*}-b^{\prime} x_{t}\right)+b^{\prime} \alpha\left(\beta^{\prime} \alpha\right)^{-1}\left(\beta^{\prime} x_{t}-\mu\right)\right] .
$$

The rule is constructed so that the position $x_{t}^{c t r}$ aims at the target value, that is, so that

$$
b^{\prime}\left(C x_{t}^{c t r}+\alpha\left(\beta^{\prime} \alpha\right)^{-1} \mu\right)=b^{*} .
$$

Figure 2 shows how the point $x_{t}$ is moved by the monetary authorities onto the dotted line. Once there, the dynamics of the process will take it towards the point on the attractor set defined by the desired target value $\pi^{*}$, provided it is moved by the central bank to the dotted line at all time points.

\section{The new process}

By applying control rule (10) the instrument variable is moved to a new position, $x_{t}^{c t r}$, from which the dynamics of the process eventually will bring the target variable to the desired value, $b^{*}$, given that the errors were switched off. But, since the process is subject to new disturbances, the process $x_{t+h},(h=1,2, \ldots)$ will drift away from $x_{t}^{c t r}$ and has to be brought back to a new position which aims at a point, for which $b^{*}$ is achieved. Thus, the above control rule has to be used at each point of time, thereby generating a new process. For this process the target variable becomes stationary around the target value, as shown below, provided the controllability condition (8) is satisfied.

The proof of this main result is given for a general linear control rule of the form $v=\kappa^{\prime} x_{t}-\kappa_{0}$ in Theorem 7 in Appendix A.1. For ease of exposition we focus here on the result for the special case (10), but when needed we will refer to some of the main results in Appendix A. We first give a result for the simple model (2) and then for model (1).

Corollary 4 Assume that $(i)$ the I(1) process $x_{t}$ is given by

$$
\Delta x_{t}=\alpha\left(\beta^{\prime} x_{t-1}-\mu\right)+\varepsilon_{t},
$$




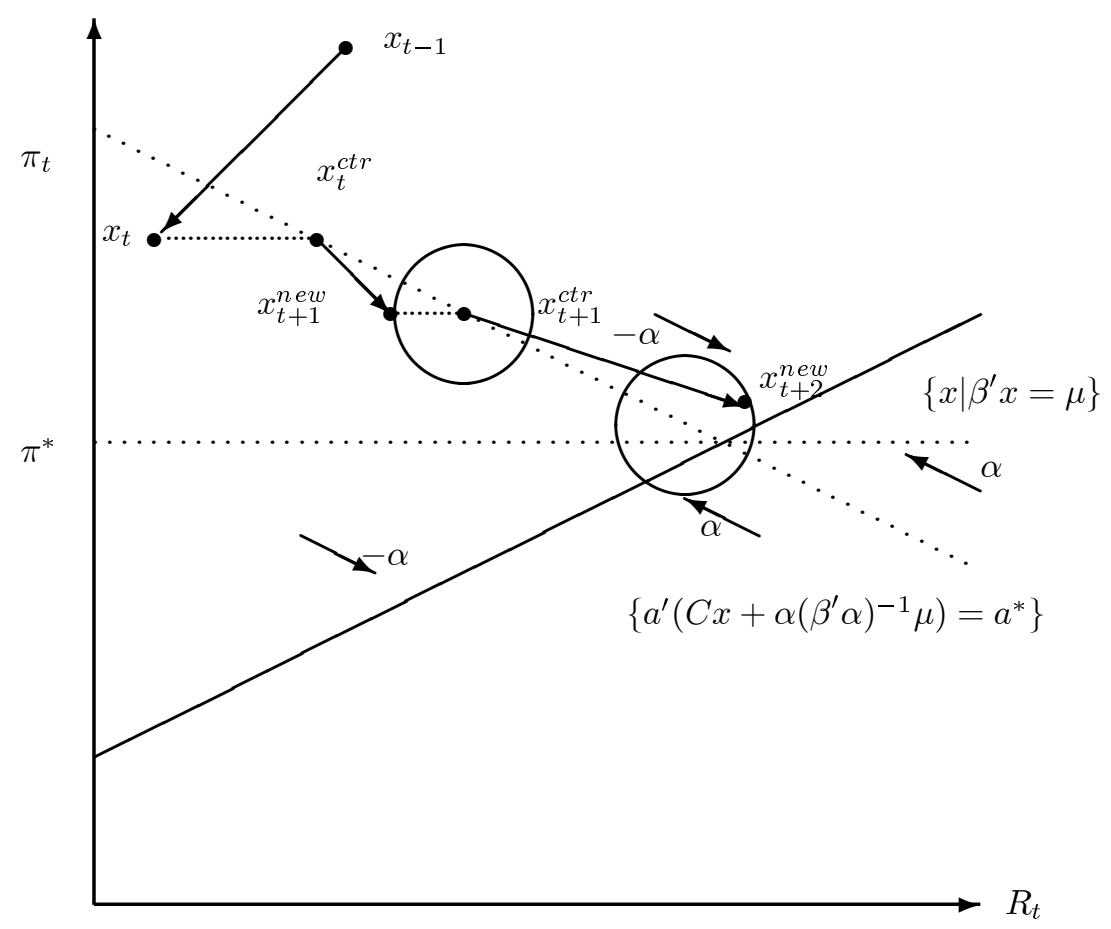

Figure 2: The point $x_{t}$ is moved by the central bank to $x_{t}^{c t r}$, and the equations generate the point $x_{t+1}^{\text {new }}$, which in a $\operatorname{VAR}(2)$ model is based upon $x_{t}^{c t r}$ and $x_{t}$. This point is moved to $x_{t+1}^{c t r}$, and the equations generate $x_{t+2}^{n e w}$ from $x_{t+1}^{c t r}$ and $x_{t}^{c t r}$. 
(ii) $\left|b^{\prime} C a\right| \neq 0$, see (4), and (iii) the control rule

$$
x_{t}^{c t r}=x_{t}+a\left(b^{\prime} C a\right)^{-1}\left(b^{*}-b^{\prime} x_{t}+b^{\prime} \alpha\left(\beta^{\prime} \alpha\right)^{-1}\left(\beta^{\prime} x_{t}-\mu\right)\right)
$$

is applied at all time points. Then the new process $x_{t}^{\text {new }}$ is an $I(1)$ cointegrated $V A R(1)$ process with cointegrating space $s p(\beta, b)$ and adjustment space sp $(\alpha, a)$. It follows that $(i) \beta^{\prime} x_{t}^{\text {new }}$ is stationary with mean $\mu,(i i) b^{\prime} x_{t}^{\text {new }}$ is stationary with mean $b^{*}$, and (iii) $b^{\prime} C x_{t}^{\text {new }}$ is white noise with mean $b^{*}-b^{\prime} \alpha\left(\beta^{\prime} \alpha\right)^{-1} \mu$.

Proof. The result follows from Theorem 7 in Appendix A.1, by choosing

$$
\kappa^{\prime}=-\left(b^{\prime} C \bar{a}\right)^{-1} b^{\prime} C, \text { and } \kappa_{0}=-\left(b^{\prime} C \bar{a}\right)^{-1}\left(b^{*}-b^{\prime} \alpha\left(\beta^{\prime} \alpha\right)^{-1} \mu\right),
$$

so that $\kappa^{\prime}$ satisfies the relations

$$
\kappa^{\prime} \alpha=0, I_{m}+\kappa^{\prime} \bar{a}=0 .
$$

Hence, the condition for stability (19) is satisfied and $\beta^{\prime} x_{t}^{\text {new }}$ is stationary with mean $\mu$, and $\kappa^{\prime} x_{t}^{\text {new }}=-\left(b^{\prime} C \bar{a}\right)^{-1} b^{\prime} C x_{t}$ is white noise around $\kappa_{0}=-\left(b^{\prime} C \bar{a}\right)^{-1}\left(b^{*}-\right.$ $\left.b^{\prime} \alpha\left(\beta^{\prime} \alpha\right)^{-1} \mu\right)$. From (4) note that

$$
b^{\prime} C x_{t}^{\text {new }}=b^{\prime} x_{t}^{\text {new }}-b^{\prime} \alpha\left(\beta^{\prime} \alpha\right)^{-1} \beta^{\prime} x_{t}^{\text {new }} .
$$

Because $\beta^{\prime} x_{t}^{\text {new }}$ is stationary with mean $\mu, b^{\prime} x_{t}^{\text {new }}$ is stationary around $b^{*}$.

In Appendix A.1 it is shown that the control rule $\kappa^{\prime} x_{t}-\kappa_{0}$ makes $\kappa^{\prime} x_{t}$ stationary. Therefore, we could simply choose $\kappa=b$ to make $b^{\prime} x_{t}$ stationary, but the results simplify considerably if $\kappa^{\prime} \alpha=0$. Since $\beta^{\prime} x_{t}$ is stationary in the controlled process, the choice of $\kappa=b+\beta \xi$, for some $\xi$, would also make $b^{\prime} x_{t}$ stationary. Therefore, we choose a $\xi$ so that $\kappa^{\prime} \alpha=b^{\prime} \alpha+\xi^{\prime} \beta^{\prime} \alpha=0$, which gives $\xi^{\prime}=-b^{\prime} \alpha\left(\beta^{\prime} \alpha\right)^{-1}$ and $\kappa^{\prime}=b^{\prime}-b^{\prime} \alpha\left(\beta^{\prime} \alpha\right)^{-1} \beta^{\prime}=b^{\prime} C$. After normalization this is precisely rule (10).

An $I(1)$ process $x_{t}$ given by (1) has a linear trend $\gamma t$. We define

$$
\Gamma=I_{p}-\sum_{i=1}^{k-1} \Gamma_{i}, \text { and } C=\beta_{\perp}\left(\alpha_{\perp}^{\prime} \Gamma \beta_{\perp}\right)^{-1} \alpha_{\perp}^{\prime} .
$$

We apply rule (10) to the detrended stacked process, see Theorem 8 in Appendix A.

Theorem 5 If (i) the I(1) process $x_{t}$ is given by the VAR(k) model (1), (ii) $\left|b^{\prime} C a\right| \neq 0$, and (iii) we apply the recursively defined control rule

$$
\begin{aligned}
x_{t}^{c t r}=x_{t}^{\text {new }}- & a\left(b^{\prime} C a\right)^{-1} b^{\prime} C\left[\left(x_{t}^{n e w}-\gamma t\right)-\sum_{i=1}^{k-1} \Gamma_{i}\left(x_{t-i}^{c t r}-\gamma(t-i)\right)\right] \\
& +a\left(b^{\prime} C a\right)^{-1}\left(b^{*}-b^{\prime}\left(I_{p}-C \Gamma\right) \bar{\beta} \mu\right)
\end{aligned}
$$

at all time points, and the new process is defined by

$$
x_{t+1}^{n e w}=x_{t}^{c t r}+\alpha\left(\beta^{\prime} x_{t}^{c t r}-\rho^{\prime} t-\mu\right)+\sum_{i=1}^{k-1} \Gamma_{i}\left(\Delta x_{t+1-i}^{c t r}-\gamma\right)+\varepsilon_{t+1},
$$


then the stacked process $\left(x_{t}^{\text {new' }}, x_{t-1}^{c t r \prime}, \ldots, x_{t-k+1}^{c t r \prime}\right)^{\prime}$ is a cointegrated VAR(1) process with $\beta^{\prime} x_{t}^{\text {new }}$ and $b^{\prime} x_{t}^{\text {new }}$ trend stationary around $\mu+\rho^{\prime} t$ and $b^{*}+b^{\prime} \gamma t$. Moreover $b^{\prime} C\left(x_{t}^{n e w}-\sum_{i=1}^{k-1} \Gamma_{i} x_{t-i}^{c t r}\right)$ is white noise around its mean.

It is sometimes convenient to rewrite the control rule as a function of the equilibrium errors, $\beta^{\prime} x_{t}^{n e w}$, deviation of target from desired target, and finally the differences of the process:

$$
\begin{aligned}
& x_{t}^{c t r}=x_{t}^{\text {new }}-a\left(b^{\prime} C a\right)^{-1}\left[b^{\prime}\left(x_{t}^{\text {new }}-\gamma t\right)-b^{*}\right. \\
& \left.\left.+b^{\prime}\left(C \Gamma-I_{p}\right) \bar{\beta}\left(\beta^{\prime} x_{t}^{\text {new }}-\rho^{\prime} t-\mu\right)+b^{\prime} C \sum_{i=1}^{k-1} \Gamma_{i}\left(x_{t}^{n e w}-x_{t-i}^{c t r}-\gamma i\right)\right)\right]
\end{aligned}
$$

Proof. This result follows from Theorem 8, by the choice

$$
\kappa_{1}^{\prime}=-\left(b^{\prime} C \bar{a}\right)^{-1} b^{\prime} C, \quad \kappa_{i}^{\prime}=\left(b^{\prime} C \bar{a}\right)^{-1} b^{\prime} C \Gamma_{i-1}, i=2, \ldots, k
$$

and

$$
\kappa_{0}=-\left(b^{\prime} C \bar{a}\right)^{-1}\left(b^{*}-b^{\prime}\left(I_{p}-C \Gamma\right) \bar{\beta} \mu\right) .
$$

Because $\alpha^{\prime} \kappa_{1}=0$, and

$$
\kappa_{i}^{\prime}=-\kappa_{1}^{\prime} \Gamma_{i-1}, i=2, \ldots, k
$$

it follows that $\tilde{\kappa}^{\prime} \tilde{\alpha}=0$, see (34). Furthermore $\kappa_{1}^{\prime} \bar{a}=-I_{m}$, and hence

$$
b^{\prime} C\left(x_{t}^{n e w}-\sum_{i=1}^{k-1} \Gamma_{i} x_{t-i}^{c t r}\right)
$$

is a white noise process around its mean.

The second expression for the control rule is seen as follows. From

$$
\begin{gathered}
C\left[\left(x_{t}^{\text {new }}-\gamma t\right)-\sum_{i=1}^{k-1} \Gamma_{i}\left(x_{t-i}^{c t r}-\gamma(t-i)\right)\right] \\
=C \Gamma\left(x_{t}^{\text {new }}-\gamma t\right)+C \sum_{i=1}^{k-1} \Gamma_{i}\left(x_{t}^{\text {new }}-x_{t-i}^{c t r}-\gamma i\right)
\end{gathered}
$$

and the relation

$$
C \Gamma=\left(C \Gamma-I_{p}\right)+I_{p}=\left(C \Gamma-I_{p}\right) \bar{\beta} \beta^{\prime}+I_{p}
$$

we find that

$$
\begin{aligned}
& b^{\prime} C \Gamma\left(x_{t}^{\text {new }}-\gamma t\right)-\left(b^{*}-b^{\prime}\left(I_{p}-C \Gamma\right) \bar{\beta} \mu\right) \\
& =b^{\prime}\left(C \Gamma-I_{p}\right) \bar{\beta}\left(\beta^{\prime}\left(x_{t}^{\text {new }}-\gamma t\right)-\mu\right)+b^{\prime}\left(x_{t}^{\text {new }}-\gamma t\right)-b^{*} .
\end{aligned}
$$

Collecting the terms we find the expression (13).

Note that $x_{t}^{\text {new }}$ is not necessarily a VAR process, as it is the stacked process that has this property.

The role of the intermediate target is given in

Proposition 6 If $c^{\prime} x_{t}$ is an intermediate target and $c^{\prime} x_{t}$ is controllable by the instrument $a^{\prime} x_{t}$, then the final target is controllable by $a^{\prime} x_{t}$. 
Proof. Let $b^{*}$ be the desired target for $b^{\prime} x_{t}$. Because $\phi b^{\prime} x_{t}+c^{\prime} x_{t}$ is stationary with some mean $m$, say, then it follows from Theorem 7 that $\phi b^{\prime} x_{t}^{\text {new }}+c^{\prime} x_{t}^{\text {new }}$ is also stationary with mean $m$. Therefore $c^{\prime} x_{t}$ is controllable and we choose to control it so that is becomes stationary with mean $m-\phi b^{*}$. It follows that

$$
b^{\prime} x_{t}^{n e w}=\phi^{-1}\left[\left(\phi b^{\prime} x_{t}^{n e w}+c^{\prime} x_{t}^{n e w}\right)-c^{\prime} x_{t}^{n e w}\right]
$$

is stationary around

$$
\phi^{-1}\left[m-\left(m-\phi b^{*}\right)\right]=b^{*} .
$$

\section{A daily model for US data ${ }^{1}$}

The theoretical results in Section 2 and 3 demonstrated that a policy control problem can be approached in two steps: In the first step we need to establish controllability of an intermediate target by the available instruments and in the second step cointegration between an intermediate target and the final target. When these conditions are satisfied we can derive an adequate inflation control rule as a function of (i) the discrepancy between the actual and desired target, (ii) the disequilibrium errors from the economy-wide steady-state relations, and (iii) the final impact of the change in the instrument on inflation.

The first part of the empirical analysis reported below deals with the relationship between the monetary instrument and the intermediate targets, whereas the analysis of the (intermediate) targets and the final targets and how they are related to the state of the economy is presented in Section 5.

The purpose of the daily analysis is first to check whether the federal funds rate has closely followed the federal target rate which is set by the Fed. Based on Proposition 6 we then investigate whether the Fed has been able to control the short-term market rates, here the three and six months treasury bill rates, using the federal funds rate.

The daily analysis is based on the data vector $x_{t}^{\prime}=\left[\operatorname{Tr}_{t}, F f_{t}, R 3_{t}, R 6_{t}\right]$, where $\operatorname{Trg}_{t}$ is the target rate set by the Federal Reserve Bank, $F f_{t}$ is the federal funds rate, $R 3_{t}$ is the three months and $R 6_{t}$ the six months tbill rate, and $t=1996.01 .02, \ldots, 1999.03 .26$, a total of 824 daily observations. All data series are from the database EcoWin. The graphs of the variables are given in Appendix B, Figures 8, 9, and 10.

Although the federal funds rate is not directly determined by the Fed the very close correspondence of the two graphs in panel (a) clearly demonstrates that for practical purposes it can be assumed set by the Fed. The remaining panels (b) and (c) show each of the tbill rates relative to the target rate. Since the target rate has generally been on a higher level than the treasury bill rates,

\footnotetext{
${ }^{1}$ All empirical results both in the daily and the monthly model have been calculated using the software program CATS in RATS (Hansen and Juselius, 1994). Some of the graphs have been produced in GiveWin (Doornik and Hendry, 1998).
} 
Table 2: Misspecification tests, characteristic roots, and weak exogeneity for the daily data

\begin{tabular}{|c|c|c|c|}
\hline Univariate tests: & $\Delta R 3_{t}$ & $\Delta R 6_{t}$ & $\overline{\Delta \Delta F f_{t}}$ \\
\hline $\mathrm{ARCH}(2)$ & 20.7 & 15.7 & 19.6 \\
\hline J.-B.(2) & 64.4 & 176.3 & 152.3 \\
\hline skewness & -0.11 & 0.03 & 0.28 \\
\hline excess kurtosis & 1.63 & 3.09 & 3.00 \\
\hline$\hat{\sigma}_{\varepsilon} \times 100$ & 0.038 & 0.037 & 0.218 \\
\hline $\mathrm{R}^{2}$ & 0.24 & 0.15 & 0.65 \\
\hline The trace test & $\begin{array}{l}504 \\
(35)\end{array}$ & $\begin{array}{c}39 \\
(20)\end{array}$ & $\begin{array}{c}4 \\
(9)\end{array}$ \\
\hline The 3 largest roots of the process $r=2$ & 1.0 & 0.91 & 0.18 \\
\hline $\begin{array}{c}\text { Test of weak exogeneity for } r=2 \text { : } \\
\qquad \chi_{0.95}^{2}(2)=6.0\end{array}$ & 7.1 & 8.7 & 460.1 \\
\hline
\end{tabular}

the graphs have been mean adjusted to facilitate a comparison. Figure 8 shows that the target rate does not satisfy the stochastic assumptions underlying the VAR model. It is, therefore, treated as an exogenous variable and model (1) is modified accordingly:

$$
\Delta y_{t}=\alpha\left(\beta^{\prime} x_{t-1}-\mu\right)+\sum_{i=1}^{k-1} \Gamma_{i} \Delta x_{t-i}+A_{0} \Delta z_{t}+\Phi D_{t}+\varepsilon_{t}, t=1, \ldots, T,
$$

where $x_{t}^{\prime}=\left[y_{t}, z_{t}\right], z_{t}=\operatorname{Tr} g_{t}, y_{t}^{\prime}=\left[F f_{t}, R 3_{t}, R 6_{t}\right]$, and $D_{t}$ is a vector of dummy variables.

\subsection{Model specification}

Altogether sixteen dummies were needed to account for extraordinary shocks influencing the federal funds rate and the tbill rates. They are as follows:

$$
\begin{array}{r}
D_{t}^{\prime}=[D 6, D 42, D 43, D I 128, D 149, D I 159, D 172, D 187, D 255, \\
D 361, D 380, D I 463, D 597, D 706, D I 713, D 765],
\end{array}
$$

where $D x$ is an $\ldots 0,0,1,0,0, \ldots$ impulse dummy describing a permanent shock at observation $t=x$ and $D I x$ is an ... $0,0,1,-1,0,0, \ldots$ dummy describing a transitory shock at observation $t=x$.

A VAR(2) produced the following misspecification tests: The multivariate LM test for first order residual autocorrelation, distributed as $\chi^{2}(9)$, gave a test statistic of 6.0 and the null of no autocorrelation was accepted with a $p$-value of 0.74 . The multivariate normality test $\chi^{2}(6)$ was strongly rejected based on a test statistic of 444.5. The univariate test values are, therefore, additionally reported in Table 2, together with the trace tests, the roots of the VAR process and weak exogeneity test of the variables. 
It appears that the residuals exhibit significant ARCH effects and that the strong rejection of normality is due to excess kurtosis but not to skewness. Since the estimation results are generally moderately robust to ARCH effects (Hansen and Rahbek, 1998) and excess kurtosis (Gonzalo, 1994) (but not skewness) we will disregard the non-normality problem here.

The trace test is consistent with $r=2$. This choice leaves a fairly large root (0.91) in the model, indicating that the adjustment to the second cointegration vector is likely to be quite slow. This is confirmed by the $\alpha_{2}$. coefficients in Table 3 and the graph of $\beta_{2}^{\prime} x_{t}$ in Figure 3 . The tests of weak exogeneity for the long-run parameters show that none of the variables can be considered weakly exogenous and that the federal funds rate is adjusting much more strongly than the treasury bill rates.

\subsection{The daily results}

In Table 3 we report an identified structure of the two long-run relations, $\hat{\beta}^{\prime} x_{t}$, and their corresponding short-run adjustment parameters, $\hat{\alpha}$. Significant coefficients are in bold face. The test of the two overidentifying restrictions (Johansen and Juselius, 1994), distributed as $\chi^{2}(2)$, produced a test statistic of 2.12 and the restrictions can be accepted with a $p$-value of 0.35 . Additional restrictions in the form of a unit coefficient on $F f_{t}$ in $\hat{\beta}_{1}$ gave a test statistic of $7.48\left(\chi^{2}(3), p\right.$ value 0.06$)$ and similarly on $R 6_{t}$ in $\hat{\beta}_{1}$ a test statistic of $8.66\left(\chi^{2}(3), p\right.$-value 0.03). Imposing unit coefficients on both relations, i.e. the test whether the two spreads, $F f_{t}-\operatorname{Trg}_{t}$ and $R 3_{t}-R 6_{t}$, span the cointegration space, was rejected based on a test statistic of $14.58\left(\chi^{2}(4), p\right.$-value 0.01$)$. Similar results were also obtained in the monthly model, hence the coefficients are left unrestricted.

The first cointegration relation confirms the visual impression from the graphs in Appendix B, Figure 10, panel (a), that the federal funds rate has been closely tracking the target rate set by the Fed. The $\hat{\alpha}_{31}$ coefficient shows that even on a daily basis the adjustment to the target rate is very fast. But, more interestingly, the tbill rates hardly react at all to deviations from the federal funds rate relation: $\hat{\alpha}_{11}$ and $\hat{\alpha}_{21}$ are close to zero, though borderline significant for the six months treasury bill rates ${ }^{2}$.

The second cointegration relation describes a 'modified' yield gap between the 3 and the 6 months tbill rates. Both are adjusting to this relation (though not very strongly so), whereas the federal funds rate is not. We interpret the results as some, but not very strong, evidence of market adjustment between the treasury bill rates (as the expectations' hypothesis would predict). ${ }^{3}$

Although the estimates of $\alpha$ demonstrated modest reaction among the market rates to the long-run relations $\beta^{\prime} x_{t}$, the estimates of $\Gamma_{1}$ and $A_{0}$ reported in Table 3 may still contain important short-run effects. The 3 months tbill

\footnotetext{
${ }^{2}$ The residual correlation between the federal funds rate and the two market rates are 0.003 and 0.017 , respectively, which strenghtens this result.

${ }^{3}$ The results from the monthly model based on an extended information set, suggest that the present information set may not be sufficient to provide a complete description of the term structure.
} 
Table 3: An overidentified representation of the cointegrating space for the daily data. (Significant values in boldface)

\begin{tabular}{|c|c|c|c|c|c|}
\hline \multicolumn{3}{|c|}{$\begin{array}{l}\text { Cointegration vectors } \beta \\
\text { t-values in brackets }\end{array}$} & \multicolumn{3}{|c|}{$\begin{array}{l}\text { Adjustment coefficients } \alpha \\
\text { t-values in brackets }\end{array}$} \\
\hline Var. & $\hat{\beta}_{1}$. & $\hat{\beta}_{2}$ & Eq. & $\hat{\alpha}_{1}$ & $\hat{\alpha}_{2}$ \\
\hline$R 3_{t}$ & 0.0 & 1.0 & $\Delta R 3_{t}$ & $\begin{array}{r}0.00 \\
(0.2)\end{array}$ & $\underset{(-2.8)}{-\mathbf{0 . 0 5}}$ \\
\hline$R 6_{t}$ & 0.0 & $\begin{array}{l}-\mathbf{0 . 8 7} \\
(-21.2)\end{array}$ & $\Delta R 6_{t}$ & $\underset{(2.0)}{\mathbf{0 . 0 1}}$ & $\begin{array}{c}\mathbf{0 . 0 4} \\
(2.4)\end{array}$ \\
\hline$F f_{t}$ & $\begin{array}{l}-0.92 \\
(-38.3)\end{array}$ & 0.0 & $\Delta F f_{t}$ & $\begin{array}{c}\mathbf{0 . 9 0} \\
(24.8)\end{array}$ & $\begin{array}{r}-0.01 \\
(-0.1)\end{array}$ \\
\hline $\operatorname{Tr} g_{t}$ & 1.0 & 0.0 & & & \\
\hline Constant & $\begin{array}{r}-0.46 \\
(-3.8) \\
\end{array}$ & $\begin{array}{r}-0.55 \\
(-2.6) \\
\end{array}$ & & & \\
\hline \multicolumn{6}{|c|}{ Short-run adjustment coefficients } \\
\hline & \multicolumn{4}{|c|}{$\Gamma_{1}$} & $A_{0}$ \\
\hline & $\Delta R 3_{t-1}$ & $\Delta R 6_{t-1}$ & $\Delta F f_{t-1}$ & $\Delta \operatorname{Tr} g_{t-1}$ & $\Delta \operatorname{Tr} g_{t}$ \\
\hline$\Delta R 3_{t}$ & $\begin{array}{l}0.05 \\
(1.1)\end{array}$ & $\begin{array}{l}0.04 \\
(0.9)\end{array}$ & $\underset{(2.0)}{\mathbf{0 . 0 1}}$ & $\begin{array}{c}-0.02 \\
(-0.2)\end{array}$ & $\begin{array}{c}0.13 \\
(2.0)\end{array}$ \\
\hline$\Delta R 6_{t}$ & $\begin{array}{c}0.01 \\
(0.3)\end{array}$ & $\begin{array}{c}0.01 \\
(0.2)\end{array}$ & $\begin{array}{c}\mathbf{0 . 0 1} \\
(2.9)\end{array}$ & $\begin{array}{l}0.13 \\
(1.7)\end{array}$ & $\begin{array}{l}0.00 \\
(0.0)\end{array}$ \\
\hline$\Delta F f_{t}$ & $\underset{(2.6)}{\mathbf{0 . 6 0}}$ & $\begin{array}{c}-\mathbf{0 . 7 6} \\
(-3.2)\end{array}$ & $\begin{array}{l}0.01 \\
(0.5)\end{array}$ & $\begin{array}{l}0.13 \\
(0.3)\end{array}$ & $\begin{array}{c}\mathbf{0 . 7 9} \\
(2.1)\end{array}$ \\
\hline
\end{tabular}

rate seems to have been affected by the current change in the target rate and the lagged change in the federal funds rate but the effects are modest and only borderline significant. The 6 months tbill rate is more significantly affected by the lagged federal funds rate. Furthermore, the federal funds rate has reacted quite strongly to the lagged change in the yield gap. This is confirmed in the monthly model.

Whether the tbill rates can be controlled or not using the federal funds rate as an instrument depends on the target/instrument elements of the long-run impact matrix. The estimated $C$ matrix is reported in Table 4 together with $\alpha_{\perp}, \tilde{\beta}_{\perp}=\beta_{\perp}\left(\alpha_{\perp}^{\prime} \Gamma \beta_{\perp}\right)^{-1}$, and $\Omega$. With $r=2$ cointegration relations, there is just one common stochastic trend, $\alpha_{\perp}^{\prime} \sum_{i=1}^{t} \hat{\varepsilon}_{i}$, where $\hat{\varepsilon}_{i}^{\prime}=\left[\hat{\varepsilon}_{R 3}, \hat{\varepsilon}_{R 6}, \hat{\varepsilon}_{F f}\right]$.

The estimate of $\alpha_{\perp}$ shows that the stochastic trend is determined mainly by cumulated shocks to the two treasury bill rates. The estimate of $\widetilde{\beta}_{\perp}$ shows that the treasury bill rates are influenced by this trend in the same proportion as the cointegration coefficients in Table 3. The federal funds rate is not affected by the stochastic trend in the treasury bill rates, but strongly affected by the weakly exogenous target rate as shown in Table 3.

The estimates of the $C$ matrix confirm the above interpretation: neither $R 3_{t}$, nor $R 6_{t}$ would be controllable according to condition (8), since they both appear to be log-run neutral with respect to $F f_{t}$. Thus they cannot serve as candidates for intermediate targets, see Definition 2, even though they may cointegrate with inflation. 

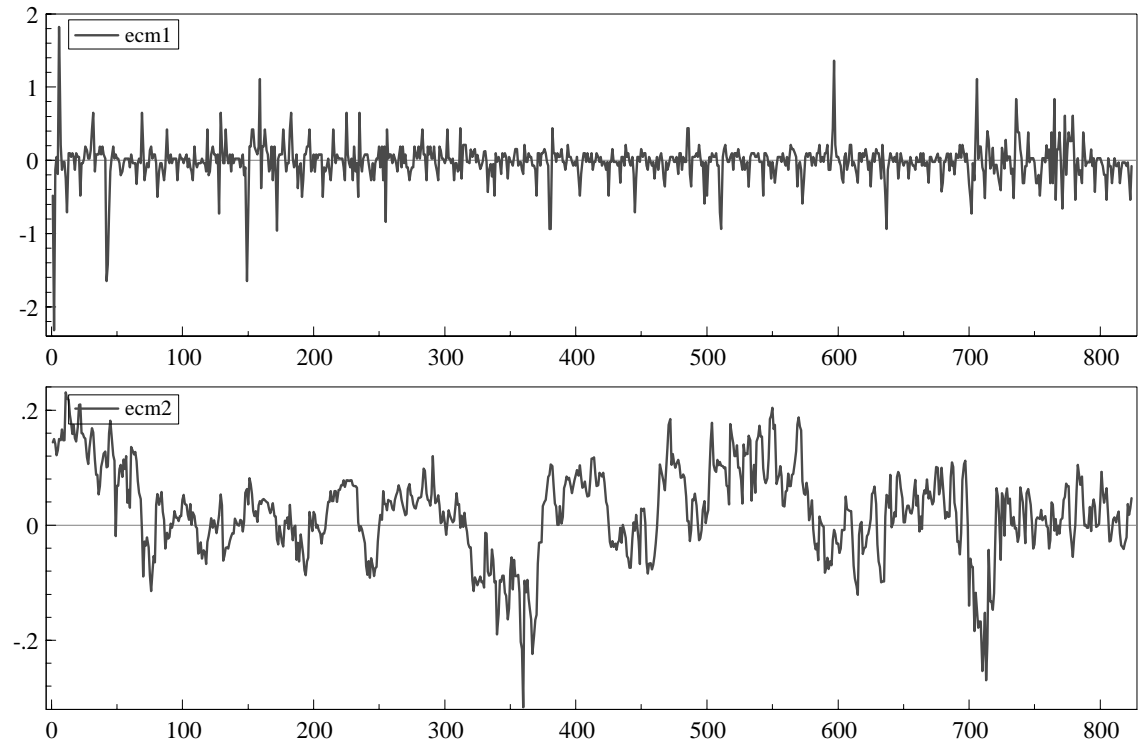

Figure 3: The graphs of the two identified cointegration relations of Table 3 for the daily data.

We have showed above that the condition for controllability of the three months tbill rate was not satisfied based on the daily analysis and the empirical analysis could stop there. Because of the strong prior belief in the Fed's ability to control inflation we have, nevertheless, continued the analysis based on monthly data and give a fairly detailed interpretation of the empirical results.

\section{$5 \quad$ The monthly US model}

In the second level of the analysis the domestic monetary transmission mechanism describes how changes in the intermediate targets, trend-adjusted money $\left(m-m^{*}\right)$ and the short-term interest rate $\left(R_{s}\right)$, dynamically affect the domestic economy through the subsequent adjustment of long-term interest rates $\left(R_{l}\right)$, the output gap $\left(y-y^{*}\right)$, and finally inflation rate $(\Delta p)$. The following simple diagram serves as an illustration:

$$
\begin{aligned}
& \text { Central bank } \\
& \text { interventions }:
\end{aligned} \longrightarrow m \stackrel{(-)}{\longrightarrow}=m^{*} \leftrightarrows \stackrel{(+)}{R_{s}} \longrightarrow \stackrel{(+)}{R_{l}} \longrightarrow y-y^{*} \longrightarrow \stackrel{(-)}{\Delta p}
$$

All four variables from the daily analysis are available on a monthly basis starting from August 1985. We therefore keep the previous variables in the model 
Table 4: The $C$-matrix and the common trends $\alpha_{\perp}$ and the associated weights $\widetilde{\beta}_{\perp}$ for the daily data

\begin{tabular}{|c|c|c|c|c|c|c|c|c|}
\hline & \multicolumn{3}{|c|}{ The $C$ matrix } & \multirow[t]{2}{*}{$\widetilde{\beta_{\perp}}$} & \multirow[t]{2}{*}{$\alpha_{\perp}$} & \multicolumn{3}{|c|}{$\widetilde{\Omega}$} \\
\hline & $\hat{\varepsilon}_{R 3}$ & $\hat{\varepsilon}_{R 6}$ & $\hat{\varepsilon}_{F f}$ & & & & & \\
\hline$R 3_{t}$ & $\begin{array}{c}\mathbf{0 . 4 5} \\
(2.5)\end{array}$ & $\begin{array}{c}\mathbf{0 . 5 2} \\
(3.5)\end{array}$ & $\begin{array}{c}-0.01 \\
(1.3)\end{array}$ & 0.87 & 0.52 & $0.038^{2}$ & & \\
\hline$R 6_{t}$ & $\begin{array}{c}\mathbf{0 . 5 3} \\
(2.5)\end{array}$ & $\begin{array}{c}0.60 \\
(3.5)\end{array}$ & $\begin{array}{l}-0.01 \\
(1.3)\end{array}$ & 1.00 & 0.60 & 0.61 & $0.037^{2}$ & \\
\hline$F f_{t}$ & $\begin{array}{r}-\mathbf{0 . 0 3} \\
(2.5)\end{array}$ & $\begin{array}{r}-\mathbf{0 . 0 4} \\
\end{array}$ & $\begin{array}{l}0.00 \\
(1.3)\end{array}$ & -0.02 & -0.04 & 0.003 & 0.017 & $0.218^{2}$ \\
\hline
\end{tabular}

and extend it with four new variables, $m-p$, real money stock in logs (M3), $y$ real GDP ${ }^{4}$ in logs, $B 10$ the 10 years bond rate, and the final target variable, $\Delta p$ monthly CPI inflation rate $(\Delta \ln C P I)$. We apply the VAR model (1) to the following eight variables

$$
x_{t}^{\prime}=[m-p, y, \Delta p, R 3, R 6, B 10, F f, \operatorname{Trg}]_{t},
$$

where $R 3, R 6, F f$, and $\operatorname{Trg}$ are monthly averages of daily observations. The nominal interest rates have been transformed to monthly rates and divided by 100 to make them comparable with monthly inflation. The sample is from 1985:8 to 1999:2, consisting of 163 monthly observations. Graphs of the monthly data are given in Appendix B, Figures 9 and 10.

\subsection{Model specification}

The target rate in Appendix B, Figure 10 looks more like a stochastic process after aggregation. Because a model for the target rate might contain information on how the Fed has set its target as a response to changing market conditions, i.e. on an implicit policy rule, it has been included as a system variable in the VAR model. ${ }^{5}$

Three dummies were needed to account for the following interventions:

$$
D_{t}^{\prime}=[D 86.03, D 86.12, D 87.11]
$$

where $D x x$, yy describes a permanent impulse dummy to the system at time $19 x x . y y$.

The results in Table 5 are based on a $\operatorname{VAR}(2)$ model. The multivariate LM test for first order residual autocorrelation, distributed as $\chi^{2}(64)$, gave a test statistic of 81.0 and was accepted with a $p$-value of 0.07 . The multivariate normality test $\chi^{2}(16)$ was rejected based on a test statistic of 87.7. Table 5 report additionally univariate misspecification tests for residual ARCH effects

\footnotetext{
${ }^{4}$ The monthly GDP values have been interpolated from quarterly data using the procedure interpolate.scr in RATS, Estima, assuming a random walk + drift model.

${ }^{5}$ As a sensitivity check the whole analysis was done with the target rate as an exogenous variable. Since the main conclusions remained unaltered, we report only the results of the full system analysis.
} 
Table 5: Misspecification tests, characteristic roots, and weak exogeneity for the monthly data

\begin{tabular}{|c|c|c|c|c|c|c|c|c|}
\hline Univ. tests: & $\overline{\Delta \Delta m_{t}}$ & $\overline{\Delta \Delta y_{t}}$ & $\overline{\Delta^{2} p_{t}}$ & 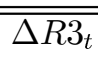 & 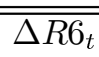 & $\overline{\Delta \Delta B 10_{t}}$ & 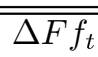 & $\overline{\Delta \operatorname{Tr} g_{t}}$ \\
\hline $\operatorname{ARCH}(2)$ & 1.6 & 0.2 & 0.1 & 15.3 & 1.8 & 0.1 & 2.1 & 13.7 \\
\hline J.-B.(2) & 0.6 & 4.8 & 6.9 & 3.6 & 0.0 & 0.8 & 1.0 & 30.0 \\
\hline$\hat{\sigma}_{\varepsilon} \times 100$ & 0.26 & 0.15 & 0.13 & 0.01 & 0.01 & 0.02 & 0.01 & 0.01 \\
\hline $\mathrm{R}^{2}$ & 0.75 & 0.66 & 0.70 & 0.49 & 0.42 & 0.37 & 0.67 & 0.52 \\
\hline Trace test: & $\begin{array}{c}335 \\
(182)\end{array}$ & $\begin{array}{l}234 \\
(146)\end{array}$ & $\begin{array}{l}156 \\
(115)\end{array}$ & $\begin{array}{c}98 \\
(87)\end{array}$ & $\begin{array}{l}\mathbf{5 2} \\
(63)\end{array}$ & $\begin{array}{l}24 \\
(42)\end{array}$ & $\begin{array}{l}11 \\
(25)\end{array}$ & $\begin{array}{c}3 \\
(12)\end{array}$ \\
\hline The roots: & 1.0 & 1.0 & 1.0 & 1.0 & 0.91 & 0.80 & 0.80 & 0.43 \\
\hline \multicolumn{9}{|c|}{ Test of weak exogeneity for $r=4$ : } \\
\hline$\chi^{2}(4)=9.5$ & 25.5 & 27.6 & 40.2 & 8.6 & 2.7 & 4.0 & 30.9 & 23.1 \\
\hline
\end{tabular}

and normality, as well as trace tests, the roots of the VAR process and weak exogeneity tests. The trace test suggests four cointegrating relations and, hence, four common trends. With the choice of $r=4$ the modulus of the largest stationary root is 0.91 in the model.

It appears that the 6 months tbill rate and the 10 years bond rate individually can be assumed weakly exogenous for the long-run parameters $\beta$, whereas the 3 months tbill rate is a borderline case. The test of joint exogeneity of the first two gave a test statistic of $9.0>\chi_{0.95}^{2}(8)$ and a $p$-value of 0.34 , whereas the test that all three are jointly exogenous was strongly rejected based on a test statistic of $53.0>\chi_{0.95}^{2}(12)$ and a $p$-value of 0.00 .

\subsection{The monthly results}

According to Definition 2 a necessary condition for controllability of a final target through the intermediate target is cointegration between an intermediate target and the final target. More generally, cointegration properties between instruments, intermediate and final targets contain important information on the monetary transmission mechanism illustrated in Table 1. Therefore, we first test cointegration between inflation rate and each of the interest rates and then between the interest rates relative to each other.

All hypotheses $\mathcal{H}_{1}-\mathcal{H}_{15}$ in Table 6 are of the form $\beta=\{H \phi, \psi\}$, i.e. they test restrictions on a single vector and leave the other vectors unrestricted (Johansen and Juselius, 1992). Except for $\mathcal{H}_{15}, H \phi$ tests whether two variables are cointegrated $(1, a)$, where $a$ is freely estimated. If there exists cointegration between pairs of variables, this procedure should find it.

The hypotheses $\mathcal{H}_{1}-\mathcal{H}_{5}$ are tests of cointegration between the inflation rate and each of the interest rates. There is weak evidence that inflation rate is cointegrated $(1,-0.4)$ with the federal funds rate (or the target rate). Among the remaining hypotheses $\mathcal{H}_{6}-\mathcal{H}_{15}$, cointegration is only found in $\mathcal{H}_{15}$ which describes the spread between the federal funds rate and the target rate. Stationarity is accepted with a $p$-value of 0.98 . The estimated coefficient between the 

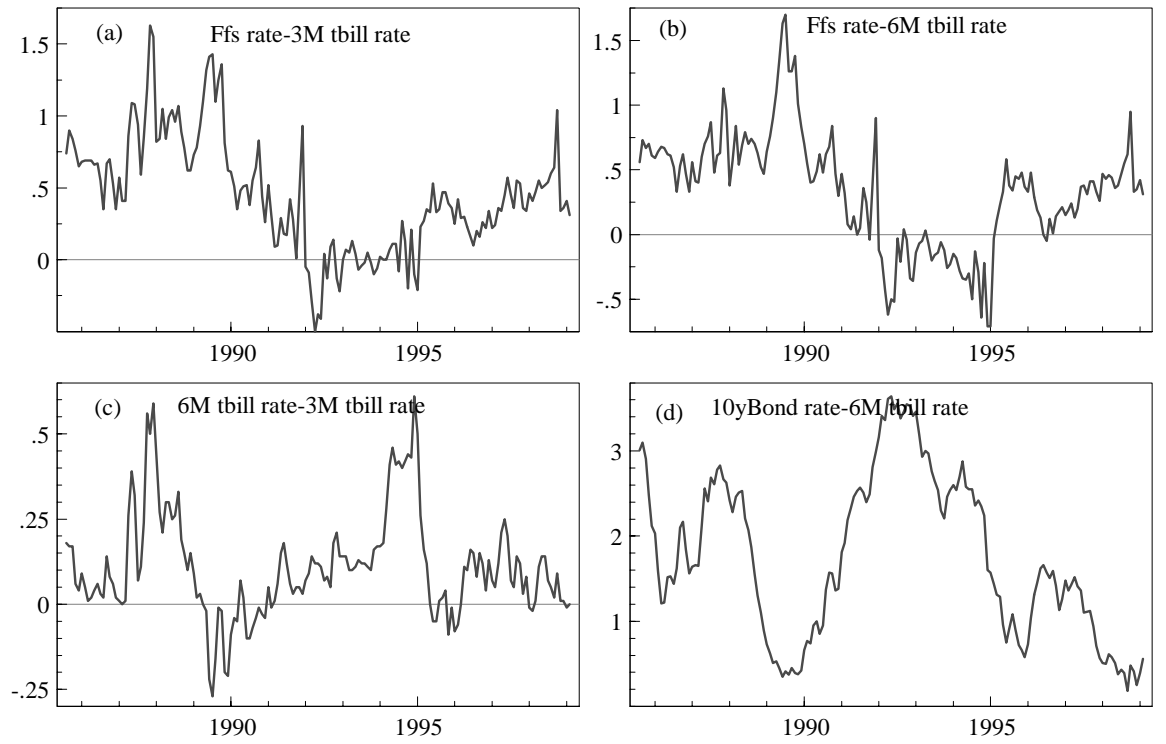

Figure 4: The graphs of the spread between (a) the federal funds rate and the 3 months tbill rate, (b) the federal funds rate and the 6 months tbill rate, (c) the 6 months tbill rate and the 3 months tbill rate, and (d) the 10 years bond rate and the 6 months tbill rate.

3 and 6 months tbill rates in $\mathcal{H}_{6}$ is close to unity, but the spread is nevertheless found to be nonstationary. See also the graph in panel (c) of Figure 4.

Although stationarity of the interest rate spread is of particular interest, it is not necessary to test this hypothesis since the less restrictive hypothesis of cointegration $(1, a)$ was already rejected in $\mathcal{H}_{1}-\mathcal{H}_{14}$. In Figure 4 the graphs of the spread between the federal funds rate and each of the tbill rates are given in panel (a) and (b), between the 3 and 6 months tbill rates in panel (c) and in panel (d) between the 10 years bond rate and the 6 month tbill rate. Although the interest rates seem to move together very closely, as illustrated by the graphs in Figure 9 in Appendix B, the spread between them, nevertheless, does not seem to be significantly mean reverting.

The policy rule in Theorem 6 defines the necessary intervention to be a function of the discrepancy between the actual and the desired target value and of the equilibrium errors in the economy, as measured by the cointegration relations $\beta^{\prime} x_{t}$. Table 7 report an identified structure of the cointegrating vectors $\hat{\beta}$ and their corresponding short-run adjustment parameters $\hat{\alpha}$. Significant coefficients are in bold face. The 8 overidentifying restrictions gave a test statistic of 5.75 , which compared to $\chi_{0.95}^{2}(8)=15.5$ can be accepted with a $p$-value of 0.68. Graphs of the four cointegrating relations are given in Fig- 
Table 6: Testing pairwise cointegration properties. Monthly data

\begin{tabular}{rrrrrrrrrrr}
\hline \hline & $m-p$ & $y$ & $\Delta p$ & $R 3$ & $R 6$ & $B 10$ & $F f$ & $T r g$ & $\chi^{2}(v)$ & p.val. \\
\hline $\mathcal{H}_{1}$ & 0 & 0 & 1 & -0.43 & 0 & 0 & 0 & 0 & $11.4(4)$ & 0.02 \\
$\mathcal{H}_{2}$ & 0 & 0 & 1 & 0 & -0.45 & 0 & 0 & 0 & $11.5(4)$ & 0.02 \\
$\mathcal{H}_{3}$ & 0 & 0 & 1 & 0 & 0 & -0.56 & 0 & 0 & $18.8(4)$ & 0.00 \\
$\mathcal{H}_{4}$ & 0 & 0 & 1 & 0 & 0 & 0 & -0.37 & 0 & $8.9(4)$ & 0.06 \\
$\mathcal{H}_{5}$ & 0 & 0 & 1 & 0 & 0 & 0 & 0 & -0.37 & $8.5(4)$ & 0.07 \\
\hline $\mathcal{H}_{6}$ & 0 & 0 & 0 & 1 & -1.04 & 0 & 0 & 0 & $19.4(4)$ & 0.00 \\
$\mathcal{H}_{7}$ & 0 & 0 & 0 & 1 & 0 & -1.56 & 0 & 0 & $26.5(4)$ & 0.00 \\
$\mathcal{H}_{8}$ & 0 & 0 & 0 & 1 & 0 & 0 & -0.81 & 0 & $20.2(4)$ & 0.00 \\
$\mathcal{H}_{9}$ & 0 & 0 & 0 & 1 & 0 & 0 & 0 & -0.81 & $20.1(4)$ & 0.00 \\
\hline $\mathcal{H}_{10}$ & 0 & 0 & 0 & 0 & 1 & -0.66 & 0 & 0 & $26.2(4)$ & 0.00 \\
$\mathcal{H}_{11}$ & 0 & 0 & 0 & 0 & 1 & 0 & -0.78 & 0 & $15.5(4)$ & 0.00 \\
$\mathcal{H}_{12}$ & 0 & 0 & 0 & 0 & 1 & 0 & 0 & -0.79 & $15.8(4)$ & 0.00 \\
\hline $\mathcal{H}_{13}$ & 0 & 0 & 0 & 0 & 0 & 1 & -0.53 & & $23.9(4)$ & 0.00 \\
$\mathcal{H}_{14}$ & 0 & 0 & 0 & 0 & 0 & 1 & 0 & -0.53 & $23.8(4)$ & 0.00 \\
$\mathcal{H}_{15}$ & 0 & 0 & 0 & 0 & 0 & 0 & 1 & -1 & $0.81(5)$ & $\mathbf{0 . 9 8}$ \\
\hline \hline
\end{tabular}

ure 5. The stability of the model parameters have been checked by the recursive test procedures discussed in (Hansen and Johansen, 1999). The recursively calculated $95 \%$ confidence sets around $\hat{\beta}_{t}$ contained $\beta_{T_{1}}$ and $\beta_{T}$ for all $t=T_{1}=1991: 6, \ldots, T=1999: 2$. The recursively calculated coefficients of $\beta_{i j}$ and $\alpha_{i j}$ showed remarkable constancy.

The first cointegration relation corresponds to $\mathcal{H}_{15}$ in Table 6 . The adjustment coefficients, $\alpha_{1}$ e show that both the target rate and the Fed rate are adjusting to the spread between the federal funds rate and the target rate, but the latter more strongly so. Note also that inflation is not significantly adjusting to this relation, nor is any of the market determined interest rates.

The second relation is a homogeneous relation between the three market rates, the 3 and 6 months tbill rates and the 10 years bond rate

$$
R 3-R 6=0.14(R 6-B 10)+\text { stat.comp. }
$$

indicating that the nonstationarity of the tbill spread is related to the nonstationarity of the spread between the bond rate and the 6 months tbill rate. The adjustment coefficients, $\alpha_{2} \bullet$, show that the federal funds rate tend to go up and money stock contract when $R 3$ is above the steady state value. This would be consistent with the Fed causing a contraction in money stock in order to increase the $F f$ rate as a response to a market increase in the short tbill rate.

The third relation seems to contain elements of an $I S$ curve and a Phillips curve relation

$$
(y-\text { trend })=0.10(m-p-\text { trend })-10.1(B 10-\Delta p)+13.4 \Delta p+\text { stat.comp } .
$$


Table 7: A fully identified representation of the cointegrating relations for the monthly model.

\begin{tabular}{|c|c|c|c|c|}
\hline \multicolumn{5}{|c|}{$\begin{array}{c}\text { Cointegration vectors } \beta \\
\text { t-values in brackets }\end{array}$} \\
\hline Var. & $\hat{\beta}_{1}$. & $\hat{\beta}_{2}$ & $\hat{\beta}_{3}$ & $\hat{\beta}_{4}$. \\
\hline$m_{t}$ & 0.0 & 0.0 & $\underset{(1.7)}{\mathbf{0 . 0 0 4}}$ & $\underset{(2.0)}{\mathbf{0 . 0 0 2}}$ \\
\hline$y_{t}$ & 0.0 & 0.0 & $\underset{(-4.4)}{-\mathbf{0 . 0 4 2}}$ & $\underset{(-4.9)}{-\mathbf{0 . 0 2 1}}$ \\
\hline$\Delta p_{t}$ & 0.0 & 0.0 & 1.0 & 0.0 \\
\hline$R 3_{t}$ & 0.0 & 1.0 & 0.0 & $\underset{(5.0)}{1.44}$ \\
\hline$R 6_{t}$ & 0.0 & $\begin{array}{l}-\mathbf{1 . 1 4} \\
(-89.6)\end{array}$ & 0.0 & $\underset{(-8.8)}{-2.64}$ \\
\hline$B 10_{t}$ & 0.0 & $\begin{array}{c}-0.15 \\
(-9.7)\end{array}$ & $\underset{(-3.1)}{-0.43}$ & 0.0 \\
\hline$F f_{t}$ & 1.0 & 0.0 & 0.0 & 0.0 \\
\hline $\operatorname{Tr}_{t}$ & -1.0 & 0.0 & 0.0 & 1.0 \\
\hline Trend & 0.0 & 0.0 & 0.000 & 0.000 \\
\hline \multicolumn{5}{|c|}{$\begin{array}{c}\text { Adjustment coefficients } \alpha \\
\text { t-values in brackets }\end{array}$} \\
\hline Eq. & $\hat{\alpha}_{1}$ & $\hat{\alpha}_{2}$ & $\hat{\alpha}_{3}$ & $\hat{\alpha}_{4}$ \\
\hline$\Delta m_{t}$ & $\begin{array}{c}-0.80 \\
(-0.4)\end{array}$ & $\begin{array}{c}-\mathbf{1 7 . 5} \\
(-4.5)\end{array}$ & $\begin{array}{l}0.23 \\
(0.9)\end{array}$ & $\begin{array}{l}4.27 \\
(4.1)\end{array}$ \\
\hline$\Delta y_{t}$ & $\begin{array}{c}-0.96 \\
(-0.8)\end{array}$ & $\begin{array}{c}-3.60 \\
(-1.7)\end{array}$ & $\begin{array}{c}\mathbf{0 . 7 6} \\
(5.0)\end{array}$ & $\begin{array}{l}\mathbf{1 . 4 7} \\
(2.5)\end{array}$ \\
\hline$\Delta^{2} p_{t}$ & $\begin{array}{l}1.31 \\
(1.3)\end{array}$ & $\begin{array}{l}2.76 \\
(1.5)\end{array}$ & $\begin{array}{c}-\mathbf{0 . 9 6} \\
(-7.4)\end{array}$ & $\begin{array}{l}-0.44 \\
(-0.9)\end{array}$ \\
\hline$\Delta R 3_{t}$ & $\begin{array}{c}-0.17 \\
(-1.7)\end{array}$ & $\begin{array}{c}-0.01 \\
(0.1)\end{array}$ & $\begin{array}{l}0.02 \\
(1.8)\end{array}$ & $\begin{array}{l}-0.06 \\
(-1.1)\end{array}$ \\
\hline$\Delta R 6_{t}$ & $\begin{array}{l}-0.20 \\
(-1.8)\end{array}$ & $\begin{array}{l}0.22 \\
(1.1)\end{array}$ & $\begin{array}{l}0.02 \\
(1.4)\end{array}$ & $\begin{array}{r}-0.05 \\
(-0.8)\end{array}$ \\
\hline$\Delta B 10_{t}$ & $\begin{array}{l}-0.01 \\
(-0.0)\end{array}$ & $\begin{array}{l}-0.18 \\
(-0.7)\end{array}$ & $\begin{array}{l}0.04 \\
(1.9)\end{array}$ & $\begin{array}{l}0.04 \\
(-0.5)\end{array}$ \\
\hline$\Delta F f_{t}$ & $\begin{array}{r}-0.48 \\
(-5.4)\end{array}$ & $\begin{array}{l}\mathbf{0 . 4 7} \\
(2.9)\end{array}$ & $\begin{array}{l}0.02 \\
(1.5)\end{array}$ & $\underset{(-4.4)}{-0.20}$ \\
\hline$\Delta \operatorname{Tr} g_{t}$ & $\begin{array}{r}\mathbf{0 . 2 9} \\
(2.6)\end{array}$ & $\begin{array}{r}0.19 \\
(0.9)\end{array}$ & $\begin{array}{l}0.01 \\
(1.0)\end{array}$ & $\underset{(-3.6)}{-0.20}$ \\
\hline
\end{tabular}



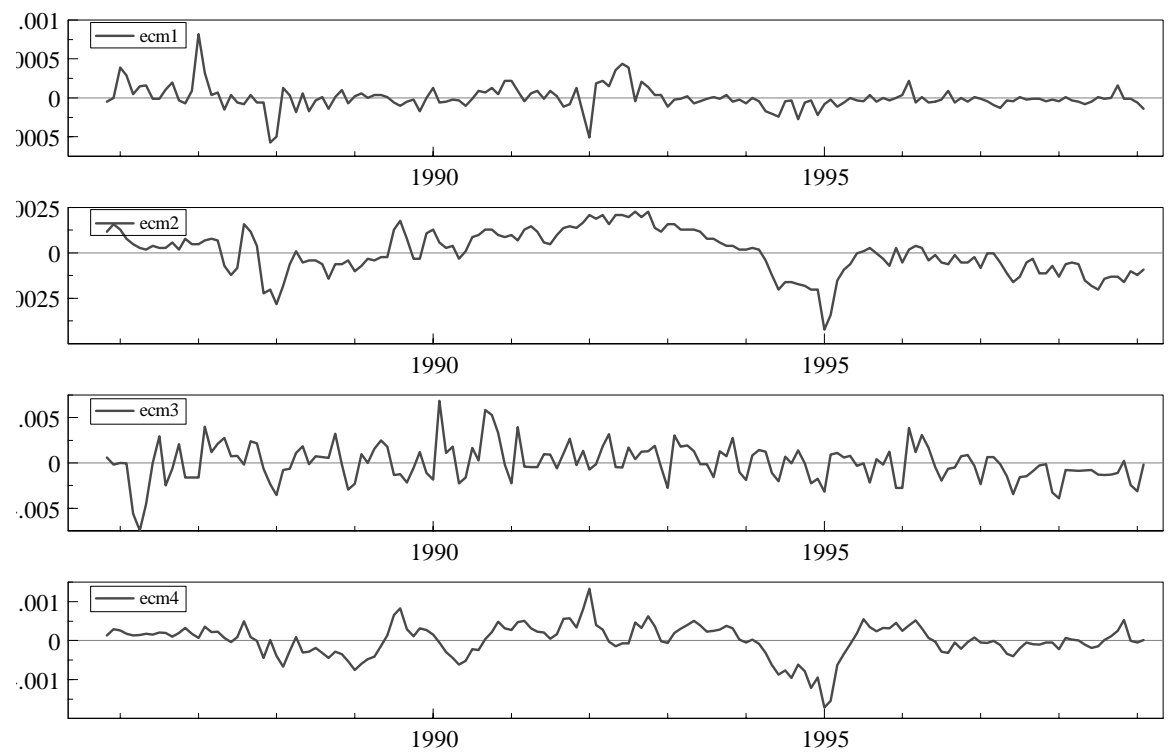

Figure 5: The graphs of the four identified cointegration relations in Table 7 for the monthly data.

Trend-adjusted real GDP is positively related to real trend-adjusted m3, negatively to real long-term interest rate (the $I S$ curve effect) and positively to the inflation rate (the Phillips curve effect). Both real GDP and inflation rate are equilibrium error correcting to this relation.

The fourth relation might be interpreted as an implicit rule for the target rate

$$
\operatorname{trg}=1.2 R 6+1.4(R 6-R 3)+0.02(y-\text { trend })-0.002(m-p-\text { trend })+\ldots
$$

indicating that the target rate has followed the 6 months tbill rate but on a $20 \%$ higher level, has been positively related to output gap, and positively to the spread between the 6 and 3 months tbill rates. The negative coefficient to trend-adjusted money stock is likely to describe the monetary contraction effect associated with an increase in central bank interest rates. The short-run adjustment coefficients, $\alpha_{4}$, show that both the target rate and the federal funds rate are significantly adjusting to this relation. In the short run both real income and real money stock react positively.

The short-run adjustment effects in $\hat{\Gamma}_{1}$ (not reported here) were altogether small and mostly insignificant. The inflation rate was significantly adjusting to the lagged change of real money stock (but negatively!), of 6 months tbill 
Table 8: The long-run impact matrix $C$ for the monthly data. (t-values in brackets)

\begin{tabular}{lcccccccc} 
& $\varepsilon_{m}$ & \multicolumn{1}{c}{$\varepsilon_{y}$} & $\varepsilon_{\Delta p}$ & $\varepsilon_{R 3}$ & $\varepsilon_{R 6}$ & $\varepsilon_{B 10}$ & $\varepsilon_{F f}$ & $\varepsilon_{T r g}$ \\
\hline$m_{t}$ & $\mathbf{3 . 9}$ & -1.3 & -1.1 & $-\mathbf{1 5 3 . 5}$ & $\mathbf{1 4 6 . 7}$ & $-\mathbf{4 9 . 7}$ & 20.2 & $\mathbf{5 8 . 2}$ \\
& $(3.2)$ & $(-0.5)$ & $(-0.4)$ & $(2.0)$ & $(1.9)$ & $(-2.3)$ & $(1.0)$ & $(2.1)$ \\
$y_{t}$ & $\mathbf{0 . 8}$ & $\mathbf{2 . 2}$ & 1.7 & -23.8 & 25.0 & $-\mathbf{1 7 . 9}$ & 8.4 & $\mathbf{1 9 . 6}$ \\
& $(2.2)$ & $(2.8)$ & $(1.8)$ & $(-1.0)$ & $(1.1)$ & $(-2.8)$ & $(1.3)$ & $(2.4)$ \\
$\Delta p_{t}$ & 0.0 & $\mathbf{0 . 2}$ & $\mathbf{0 . 1}$ & -0.2 & -1.2 & 0.5 & $\mathbf{0 . 9}$ & 0.5 \\
& $(0.2)$ & $(4.0)$ & $(3.1)$ & $(-0.2)$ & $(-1.1)$ & $(1.5)$ & $(2.9)$ & $(1.4)$ \\
$R 3_{t}$ & 0.04 & $\mathbf{0 . 1 4}$ & $\mathbf{0 . 1 4}$ & -1.10 & 2.46 & -0.22 & 0.11 & 0.90 \\
& $(1.3)$ & $(2.3)$ & $(2.0)$ & $(-0.6)$ & $(1.3)$ & $(-0.4)$ & $(0.2)$ & $(1.4)$ \\
$R 6_{t}$ & 0.03 & $\mathbf{0 . 1 2}$ & $\mathbf{0 . 1 3}$ & -1.07 & 2.32 & -0.09 & 0.10 & 0.80 \\
& $(1.2)$ & $(2.1)$ & $(1.9)$ & $(-0.6)$ & $(1.4)$ & $(-0.2)$ & $(0.2)$ & $(1.3)$ \\
$B 10_{t}$ & -0.00 & 0.01 & 0.04 & -0.51 & 0.03 & $\mathbf{1 . 0 7}$ & 0.31 & 0.02 \\
\multirow{2}{*}{$F f_{t}$} & $(0.0)$ & $(0.2)$ & $(1.0)$ & $(-0.5)$ & $(0.0)$ & $(3.6)$ & $(1.1)$ & $(0.1)$ \\
& 0.04 & $\mathbf{0 . 1 9}$ & $\mathbf{0 . 1 9}$ & -1.22 & 2.00 & 0.04 & 0.46 & 1.08 \\
\multirow{T}{*}{${ }_{r} g_{t}$} & $(1.1)$ & $(2.7)$ & $(2.3)$ & $(-0.6)$ & $(1.0)$ & $(0.1)$ & $(0.8)$ & $(1.5)$ \\
& 0.04 & $\mathbf{0 . 1 9}$ & $\mathbf{0 . 1 9}$ & -1.18 & 1.94 & 0.05 & 0.47 & 1.08 \\
& $(1.1)$ & $(2.8)$ & $(2.4)$ & $(-0.6)$ & $(1.0)$ & $(0.1)$ & $(0.9)$ & $(1.5)$ \\
\hline \hline
\end{tabular}

Note: The large coefficients to interest rates in the first two rows are due to the data transformation described at the beginning of Section 6 .

rate (negatively), and of the long-term bond rate (positively). Lagged changes of output gap had positive effects on essentially all the interest rates. Lagged changes of the federal funds rate and the target rate had no significant effects on any of the variables.

Whether inflation is controllable or not is crucially dependent on the longrun impact matrix, $C$. Table 8 reports the estimated $\hat{C}$. The condition that inflation can be controlled by the Fed (using the federal funds rate) is that $c_{37} \neq 0$ (or, because of the strong cointegration between $F t$ and $\operatorname{Trg}, c_{38} \neq 0$ ) in the $C$ matrix. Both coefficients are positive (against the prior belief of a negative impact on inflation in the long run), but only the federal funds rate $c_{37}$ is significant in Table 8.

The above results suggest that shocks to the federal funds rate have primarily had a cost-push effect on inflation. The two negative elements in the inflation row, $c_{34}$ and $c_{35}$, corresponding to the tbill rates, are not significantly different from zero. The most significant long-run impact on inflation is from shocks to the output gap, possibly signifying a 'demand-pull' effect on inflation. Hence, the widely held belief that the Fed can bring US CPI inflation down by increasing the federal funds rate does not obtain empirical support.

\subsection{Simulating the new process}

As an example of the effect of rule (13) on the variables in the economy, we have used the estimated parameters and residuals from the VAR model of this section to generate the process $x_{t}^{\text {new }}$ based on (12):

$$
x_{t+1}^{n e w}=x_{t}^{c t r}+\hat{\alpha}\left(\hat{\beta}^{\prime} x_{t}^{c t r}-\hat{\mu}\right)+\hat{\Gamma}_{1} \Delta x_{t}^{c t r}+\hat{\Phi} D_{t+1}+\hat{\varepsilon}_{t+1} .
$$


Without interventions the process $x_{t}$ would be generated by:

$$
x_{t+1}=x_{t}+\hat{\alpha}\left(\hat{\beta}^{\prime} x_{t}-\hat{\mu}\right)+\hat{\Gamma}_{1} \Delta x_{t}+\hat{\Phi} D_{t+1}+\hat{\varepsilon}_{t+1} .
$$

By subtracting $x_{t+1}$ from $x_{t+1}^{\text {new }}$ we find an expression for $x_{t+1}^{\text {new }}$ in terms of $x_{t+1}, x_{t}, \Delta x_{t}, x_{t}^{c t r}$ and $\Delta x_{t}^{c t r}$ given by:

$$
x_{t+1}^{\text {new }}=x_{t+1}+\left(I_{p}+\hat{\alpha} \hat{\beta}^{\prime}\right)\left(x_{t}^{c t r}-x_{t}\right)+\hat{\Gamma}_{1} \Delta\left(x_{t}^{c t r}-x_{t}\right),
$$

which together with (13)

$$
\begin{gathered}
x_{t}^{c t r}=x_{t}^{\text {new }}-a\left(b^{\prime} \hat{C} a\right)^{-1}\left[b^{\prime} x_{t}^{n e w}-b^{*}+b^{\prime}\left(\hat{C} \hat{\Gamma}-I_{p}\right) \hat{\beta}\left(\hat{\beta}^{\prime} \hat{\beta}\right)^{-1}\left(\hat{\beta}^{\prime} x_{t}^{n e w}-\hat{\mu}\right)\right. \\
\left.+b^{\prime} \hat{C} \hat{\Gamma}_{1}\left(x_{t}^{\text {new }}-x_{t-1}^{c t r}\right)\right]
\end{gathered}
$$

can be used to derive the new process. The intervention, given by the difference $a^{\prime}\left(x_{t}^{c t r}-x_{t}^{\text {new }}\right)$, is graphed in Figure 6 together with the Federal Funds rate. The additional interventions needed to make inflation stationary are very small indeed. The derived interventions and the observed VAR residuals are negatively correlated suggesting that the former comprise a small negative correction of the actual 'shocks' to the federal funds rate.

Because the long-run impact of permanent shocks to the federal funds rate was significant (though positive), inflation is controllable. By applying the control rule (13), inflation would have become stationary around a target mean of $2 \%$ as illustrated in Figure 7. However, the difference between the 'new controlled' inflation rate and the observed inflation is not very large in this period.

\section{Conclusions}

Based on the cointegrated VAR model this paper has derived a simple policy control rule related to the discrepancy between the actual and desired value of the target variable, and to the equilibrium errors in the economy as described by the cointegrating relations. The results are given for the case when the number of targets are the same as the number of instruments and when the objective is to change a given process to a stationary process with a mean given by the desired target value. When the control rule is applied at all time points the dynamics of the target variable change as a result of intervening in the market, but the parameters of the other equations of the model do not change. The new process is still generated by a VAR model in which the target variable is now stationary around the target value. This result holds under controllability, expressed as a condition on the elements of the long-run impact matrix.

The theoretical results were applied to US monetary data. In the period examined the most important instrument used by the Federal Reserve Bank was open market operations with the purpose of changing the federal funds rate to make it follow the Fed's target rate. Assuming that this first control operation works well (as it obviously does), standard theory assumes that an 


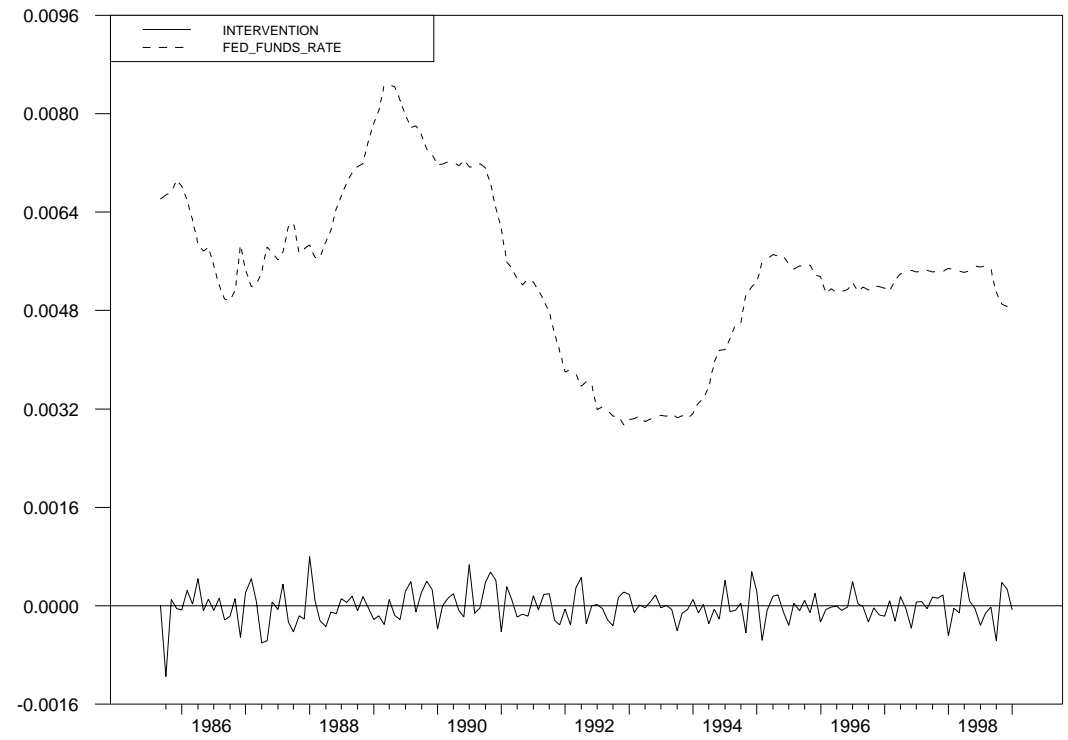

Figure 6: Graphs of the federal funds rate (dotted line) and the derived interventions, $F f_{t}^{c t r}-F f_{t}^{\text {new }}$ (solid line). 


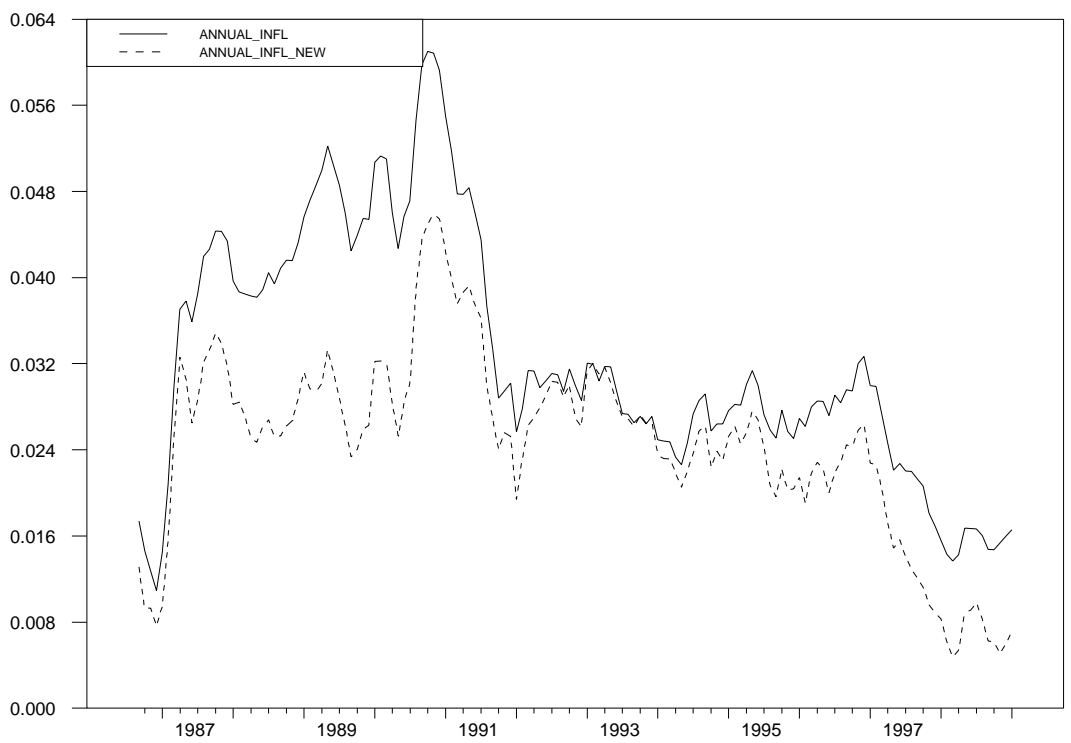

Figure 7: Annual inflation (solid line) and the new annual inflation (dotted line), using the control rule (13) at all time points. 
intervention to the federal funds rate first changes the short-term market rates, then the long-term market rates and, finally, via the transmission mechanism of the economy, the final target (the goal) variable in the desired direction. The effectiveness of monetary policy is thus dependent on there being an exploitable relationship from the intermediate target via the macroeconomic transmission mechanism to the final target, the inflation rate.

The empirical assessment was done in two steps: In the first step the controllability of an intermediate target (the 3 months tbill rate) by the Fed was examined based on daily data. In the second step the transmission mechanism from the federal funds rate to short-term market rates and from the latter to the macroeconomy and the inflation rate was estimated based on monthly data. In both steps the claim that inflation can be controlled by the Federal Reserve Bank increasing the federal funds rate did not receive empirical support using the definitions and modelling framework discussed here.

Three important conditions needed for short-term interest rate control to work as desired did not receive empirical support in the data:

1. The Fisher parity, which assumes that expected inflation is determining nominal interest rates and that real interest rate is constant or stationary.

2. The expectations hypothesis of interest rates, which assumes that the spread between interest rates of different maturities should be stationary and consequently that one common trend is driving the interest rates.

3. The link between interest rates of different maturity, that is assumed to run from the short rates set by the central bank to the long-term market rates.

None of the nominal interest rates (the federal funds rate, the 3 and 6 months treasury bill rates, and the 10 years government bond rate) appeared cointegrated with CPI inflation rate (which under weak assumptions of rational agents should be cointegrated with expected inflation). Consistent with this (Juselius, 1999) we found that the spreads were not pair-wise stationary, indicating more than one common trend in the term structure of this period. Nevertheless, homogeneity between the market rates was accepted demonstrating the close links between nominal market rates. Finally, the link was from the long-term bond rate to the shorter end of the term structure, as defined by the weak exogeneity tests and the estimated adjustment dynamics, and not the other way around. This is consistent with the results in Juselius and MacDonald (2000a, 2000b) where domestic and foreign transmission effects on inflation, interest rates, and real exchange rates were investigated.

Several other empirical studies based on European data have similarly found monetary effects on inflation to be negligible in the last decades of increased globalization and capital liberalization (Juselius, 1998). Also, the role of inflationary expectations and their effect on forward (wage) contracts, and of excess aggregate demand for demand-pull inflation seem to have become less significant 
(Juselius, 2000). Therefore, central banks seem to primarily have caused costpush inflation when increasing interest rates to curb inflationary expectations and to decrease demand-pull effects on inflation.

\section{$7 \quad$ References}

Bedini, C. And R. Mosconi (2000): "New tools for the dynamic analysis of cointegrated VAR models," Dipartimento di Economica e Produzione, Politecnico di Milano. www.ecopro.polimi.it/home/Rocco.Mosconi

Bruneau, C. And E. Jondeau (1999): "Long-run causality with an application to international links between long-term interest rates," Oxford Bulletin of Economics and Statistics, 61, 545-568.

Clarida, R., J. Gali, and M. Gertler (1998): "Monetary policy rules in practice. Some international evidence," European Economic Review, 42, 10331067.

Doornik, J.A. And D.F. Hendry (1998), GiveWin. An interface to empirical modelling, Timberlake Consultants.

EcoWin, (1999): Gothenburg: Hansen and Partners AB, www.ecowin.com.

Gonzalo, J. (1994): "Five alternative methods of estimating long-run equilibrium relationships," Journal of Econometrics, 60, 203-233.

Hansen, H. AND S. Johansen (1999): "Some tests for parameter constancy in the cointegrated VAR," Econometrics Journal, 2, 306-333.

Hansen, H. And K. Juselius (1994): CATS in RATS, Manual to Cointegration Analysis of Time Series. Evanston: ESTIMA, www.estima.com.

HANSEN, E. AND A. RAhBeK (1998): "Stationarity and asymptotics of multivariate ARCH time series with an application to robustness of cointegration analysis," Department of Theoretical Statistics, University of Copenhagen, http://www.stat.ku.dk/ rahbek/.

Johansen, S. (1996): Likelihood-based Inference in Cointegrated Vector Autoregressive Models. Oxford: Oxford University Press.

Johansen, S. And Juselius, K. (1992): "Testing structural hypotheses in a multivariate cointegration analysis of the PPP and the UIP for UK," Journal of Econometrics 53, 211-244.

Johansen, S. And Juselius, K. (1994): "Identification of the long-run and the short-run structure. An application to the ISLM model," Journal of Econometrics, 63, 7-36.

JuSELIUS, K. (1998): "Changing monetary transmission mechanisms within the EU," Empirical Economics, 23, 455-481.

JusELIUs, K. (1999): "Models and relations in economics and econometrics," Journal of Economic Methodology, 6, 259-290.

JusELius, K. (2000): "Economic aspects of joining the EMU: Reflections after the Danish no," Institute of Economics, University of Copenhagen, www.econ.ku/okokj.

Juselius, K. AND R. MACDONALD (2000a): "International parity relationships between Germany and the United States: a joint modelling approach," Submitted for publication, www.econ.ku/okokj. 
Juselius, K. AND R. MacDonald (2000b): "Interest rate and price linkages between the USA and Japan: Evidence from the post Bretton Woods period," Submitted for publication, www.econ.ku/okokj.

Preston, A. J. And A. R. Pagan (1982): The Theory of Economic Policy, Statics and Dynamics. Cambridge: Cambridge University Press.

Proietti, T. (1997): "Short run dynamics in cointegrated systems," Oxford Bulletin of Economics and Statistics, 59, 405-422.

TAYLOR, J. (1993): "Discretion versus policy rules in practice," CarnegieRochester Conference Series on Public Policy, 39, 195-214.

TAYlor, J. (ed.) (1999): Monetary Policy Rules. Chicago: University of Chicago Press. 


\section{A Appendix: Linear control rules}

The purpose of this Appendix is to present a more general formulation of the simple linear control rule discussed in the main bulk of the paper. Applications of control theory in economics have been extensively treated for stationary data, see for example Preston and Pagan (1982), but not in the context of cointegrated VAR models. Therefore, the results here are almost exclusively derived for the latter models.

The general objective is to change some target variables so that they become stationary with the mean given by the desired target values. The results are derived for the case when the number of targets is the same as the number of instruments. By applying the control rule at all points of time the dynamics of the process change and we need to derive the properties of the process resulting from the new model. The main result is given in Section A.1, Theorem 7, for the control of a nonstationary process with one lag and no trend, and extended in Section A.2 to a process with several lags and a trend. Finally, in Section A.3 we give the results for how to change the mean of a stationary target variable to become the desired target value.

\section{A.1 A general linear control rule}

We assume here that the simple VAR(1) model (2) describes the macroeconomy and define a general linear control rule from a $p \times m$ matrix $\kappa$, and an $m$ vector $\kappa_{0}$ by

$$
x_{t}^{c t r}=x_{t}+\bar{a}\left(\kappa^{\prime} x_{t}-\kappa_{0}\right) .
$$

When applying the rule at all time points we create a new model which generates the new process $x_{t}^{\text {new }}$. Based on $x_{t}^{\text {new }}$ the central bank chooses an intervention given by the control rule

$$
x_{t}^{c t r}=\left(I_{p}+\bar{a} \kappa^{\prime}\right) x_{t}^{n e w}-\bar{a} \kappa_{0} .
$$

The market on the other hand generates the next value of the new process based on model (2)

$$
x_{t+1}^{n e w}=\left(I_{p}+\alpha \beta^{\prime}\right) x_{t}^{c t r}-\alpha \mu+\varepsilon_{t+1} .
$$

We then prove

Theorem 7 If $x_{t}$ is given by the model

$$
\Delta x_{t}=\alpha\left(\beta^{\prime} x_{t-1}-\mu\right)+\varepsilon_{t}
$$

and we apply the control rule

$$
x_{t}^{c t r}=x_{t}+\bar{a}\left(\kappa^{\prime} x_{t}-\kappa_{0}\right),
$$

at all time points, then the new process $x_{t}^{\text {new }}$ is given by a VAR(1) model. 
The new process is an $I(1)$ process with $(r+m)$-dimensional cointegrating space $\operatorname{sp}(\beta, \kappa)$ and adjustment space $\operatorname{sp}(\alpha, a)$, if and only if

$$
\left|\operatorname{eig}\left(\begin{array}{cc}
I_{r}+\beta^{\prime} \alpha & \left(I_{r}+\beta^{\prime} \alpha\right) \beta^{\prime} \bar{a} \\
\kappa^{\prime} \alpha & I_{m}+\kappa^{\prime}\left(I_{p}+\alpha \beta^{\prime}\right) \bar{a}
\end{array}\right)\right|<1
$$

In this case

$$
\left|\kappa^{\prime} C a\right| \neq 0
$$

and $(\beta, \kappa)^{\prime} x_{t}^{\text {new }}$ is stationary with mean $\left(\mu^{\prime}, \kappa_{0}^{\prime}\right)^{\prime}$ and a long-run impact matrix given by

$$
C^{\text {new }}=C-C a\left(\kappa^{\prime} C a\right)^{-1} \kappa^{\prime} C .
$$

If $\kappa^{\prime} \alpha=0$, then $\kappa^{\prime} x_{t}^{\text {new }}$ is VAR(1) with coefficient matrix $I_{m}+\kappa^{\prime} \bar{a}$. Hence, it is white noise around $\kappa_{0}$ if and only if

$$
I_{m}+\kappa^{\prime} \bar{a}=0 .
$$

Thus, by adding $\bar{a}\left(\kappa^{\prime} x_{t}-\kappa_{0}\right)$ to the process at all time points we remove $m$ unit roots, if condition (19) is satisfied. This condition rules out explosive roots, not only of the new combinations $\kappa^{\prime} x_{t}^{\text {new }}$ but also for $\beta^{\prime} x_{t}^{\text {new }}$. It is therefore needed for the new process $(\beta, \kappa)^{\prime} x_{t}^{\text {new }}$ to be stationary. In particular, if we choose $\kappa^{\prime} \alpha=0$, the results simplify considerably, and the process $\kappa^{\prime} x_{t}^{\text {new }}$ becomes autoregressive and under (22) even white noise. If $\kappa^{\prime} \alpha=0$, the stationary roots of the original process are also roots of the new process.

The important necessary condition for achieving stationarity of the variable $\kappa^{\prime} x_{t}$ is given by $\left|\kappa^{\prime} C a\right| \neq 0$, see (20). Thus, in the example in Section 2 we can make the nonstationary inflation rate $\pi_{t}$ stationary using the interest rate $R_{t}$ as an instrument provided the relevant element of the $C$ matrix is nonzero:

$$
C_{\pi, R} \neq 0 .
$$

Proof. Substituting (16) into (17) we derive the equation for the new process

$$
x_{t+1}^{n e w}=\left(I_{p}+\alpha \beta^{\prime}\right)\left(\left(I_{p}+\bar{a} \kappa^{\prime}\right) x_{t}^{n e w}-\bar{a} \kappa_{0}\right)-\alpha \mu+\varepsilon_{t+1}
$$

or

$$
\Delta x_{t+1}^{\text {new }}=\left(\alpha,\left(I_{p}+\alpha \beta^{\prime}\right) \bar{a}\right)\left(\begin{array}{c}
\beta^{\prime} x_{t}^{\text {new }}-\mu \\
\kappa^{\prime} x_{t}^{\text {new }}-\kappa_{0}
\end{array}\right)+\varepsilon_{t+1},
$$

which define a $\operatorname{VAR}(1)$ model for $x_{t}^{\text {new }}$. Condition (3) for the process to be a cointegrated $I(1)$ process is given by (19). If (19) is satisfied then

$$
\left|\left(\begin{array}{cc}
\beta^{\prime} \alpha & \left(I_{r}+\beta^{\prime} \alpha\right) \beta^{\prime} a \\
\kappa^{\prime} \alpha & \kappa^{\prime}\left(I_{p}+\alpha \beta^{\prime}\right) a
\end{array}\right)\right|=\left|\beta^{\prime} \alpha\right|\left|\kappa^{\prime} \bar{a}-\kappa^{\prime} \alpha\left(\beta^{\prime} \alpha\right)^{-1} \beta^{\prime} a\right|=\left|\beta^{\prime} \alpha\right|\left|\kappa^{\prime} C a\right|
$$


is nonzero, which proves (20). If condition (19) holds there are $m+r$ cointegrating vectors $(\beta, \kappa)$ and the adjustment coefficients have changed to

$$
\alpha^{\text {new }}=\left(\alpha,\left(I_{p}+\alpha \beta^{\prime}\right) \bar{a}\right)
$$

Hence,

$$
s p\left(\alpha^{n e w}\right)=s p(\alpha, a) .
$$

If $\kappa^{\prime} \alpha=0$, condition (19) simplifies to

$$
\left|e i g\left(\begin{array}{cc}
I_{r}+\beta^{\prime} \alpha & \left(I_{r}+\beta^{\prime} \alpha\right) \beta^{\prime} \bar{a} \\
0 & I_{m}+\kappa^{\prime} \bar{a}
\end{array}\right)\right|<1,
$$

which is equivalent to

$$
\left|e i g\left(I_{r}+\beta^{\prime} \alpha\right)\right|<1 \text { and }\left|e i g\left(I_{m}+\kappa^{\prime} \bar{a}\right)\right|<1 .
$$

Multiplying (23) by $\kappa^{\prime}$, for which $\kappa^{\prime} \alpha=0$, we find an equation for $\kappa^{\prime} x_{t}^{\text {new }}$ :

$$
\kappa^{\prime} \Delta x_{t+1}^{n e w}=\kappa^{\prime} \bar{a}\left(\kappa^{\prime} x_{t}^{n e w}-\kappa_{0}\right)+\kappa^{\prime} \varepsilon_{t+1},
$$

which shows that $\kappa^{\prime} x_{t}^{\text {new }}$ is a $\operatorname{VAR}(1)$ process. If in addition $\kappa^{\prime} \bar{a}=-I_{m}$, it is white noise around its mean.

To derive the new matrix $C^{\text {new }}$ we first calculate

$$
\left(\begin{array}{ll}
\beta^{\prime} \alpha & \beta^{\prime}\left(I_{p}+\alpha \beta^{\prime}\right) \bar{a} \\
\kappa^{\prime} \alpha & \kappa^{\prime}\left(I_{p}+\alpha \beta^{\prime}\right) \bar{a}
\end{array}\right)^{-1}=\left(\begin{array}{ll}
A_{11} & A_{12} \\
A_{21} & A_{22}
\end{array}\right)
$$

where

$$
\begin{aligned}
& A_{11}=\left(\beta^{\prime} \alpha\right)^{-1}+\left(\beta^{\prime} \alpha\right)^{-1} \beta^{\prime}\left(I_{p}+\alpha \beta^{\prime}\right) \bar{a}\left(\kappa^{\prime} C \bar{a}\right)^{-1} \kappa^{\prime} \alpha\left(\beta^{\prime} \alpha\right)^{-1} \\
& A_{21}=-\left(\kappa^{\prime} C \bar{a}\right)^{-1} \kappa^{\prime} \alpha\left(\beta^{\prime} \alpha\right)^{-1} \\
& A_{12}=-\left(\beta^{\prime} \alpha\right)^{-1} \beta^{\prime}\left(I_{p}+\alpha \beta^{\prime}\right) \bar{a}\left(\kappa^{\prime} C \bar{a}\right)^{-1} \\
& A_{22}=\left(\kappa^{\prime} C \bar{a}\right)^{-1}
\end{aligned}
$$

and then find

$$
C^{\text {new }}=I_{p}-\left(\alpha,\left(I_{p}+\alpha \beta^{\prime}\right) \bar{a}\right)\left(\begin{array}{ll}
\beta^{\prime} \alpha & \beta^{\prime}\left(I_{p}+\alpha \beta^{\prime}\right) \bar{a} \\
\kappa^{\prime} \alpha & \kappa^{\prime}\left(I_{p}+\alpha \beta^{\prime}\right) \bar{a}
\end{array}\right)^{-1}(\beta, \kappa)^{\prime}
$$

which reduces to the expression given in (21).

\section{A.2 A model with several lags and a linear trend}

Next we apply the main result in Theorem 7 to a model with more lags and a linear trend. We allow the control rule to depend on deviations from trend of current and lagged observations:

$$
x_{t}^{c t r}=x_{t}+\bar{a}\left(\sum_{i=1}^{k} \kappa_{i}^{\prime}\left(x_{t-i+1}-\gamma(t-i+1)\right)-\kappa_{0}\right) .
$$


It is convenient to introduce the stacked process. To keep notation simple we assume here that $k=3$ and define

$$
\tilde{x}_{t}=\left(\begin{array}{l}
x_{t}-\gamma t \\
x_{t-1}-\gamma(t-1) \\
x_{t-2}-\gamma(t-2)
\end{array}\right), \tilde{\varepsilon}_{t}=\left(\begin{array}{c}
\varepsilon_{t} \\
0 \\
0
\end{array}\right), \tilde{\mu}=\left(\begin{array}{c}
\mu \\
0 \\
0
\end{array}\right),
$$

and write (1) as an error correction model in companion form

$$
\Delta \tilde{x}_{t}=\tilde{\alpha}\left(\tilde{\beta}^{\prime} \tilde{x}_{t-1}-\tilde{\mu}\right)+\tilde{\varepsilon}_{t},
$$

where

$$
\begin{gathered}
\tilde{\alpha}=\left(\begin{array}{ccc}
\alpha & \Gamma_{1} & \Gamma_{2} \\
0 & I_{p} & 0 \\
0 & 0 & I_{p}
\end{array}\right), \tilde{\alpha}_{\perp}=\left(\begin{array}{c}
\alpha_{\perp} \\
-\Gamma_{1}^{\prime} \alpha_{\perp} \\
-\Gamma_{2}^{\prime} \alpha_{\perp}
\end{array}\right), \\
\tilde{\beta}=\left(\begin{array}{rrr}
\beta & I_{p} & 0 \\
0 & -I_{p} & I_{p} \\
0 & 0 & -I_{p}
\end{array}\right), \tilde{\beta}_{\perp}=\left(\begin{array}{c}
\beta_{\perp} \\
\beta_{\perp} \\
\beta_{\perp}
\end{array}\right) .
\end{gathered}
$$

We find

$$
\tilde{\alpha}_{\perp}^{\prime} \tilde{\beta}_{\perp}=\alpha_{\perp}^{\prime}\left(I_{p}-\Gamma_{1}-\Gamma_{2}\right) \beta_{\perp}=\alpha_{\perp}^{\prime} \Gamma \beta_{\perp},
$$

which for an $I(1)$ process has full rank, (Johansen 1996, Theorem 4.2). Finally, we find the long-run impact matrix

$$
\tilde{C}=\tilde{\beta}_{\perp}\left(\tilde{\alpha}_{\perp}^{\prime} \tilde{\beta}_{\perp}\right)^{-1} \tilde{\alpha}_{\perp}^{\prime}=\left(\begin{array}{c}
I_{p} \\
I_{p} \\
I_{p}
\end{array}\right) C\left(\begin{array}{c}
I_{p} \\
-\Gamma_{1}^{\prime} \\
-\Gamma_{2}^{\prime}
\end{array}\right)^{\prime}
$$

where

$$
C=\beta_{\perp}\left(\alpha_{\perp}^{\prime} \Gamma \beta_{\perp}\right)^{-1} \alpha_{\perp}^{\prime} .
$$

We now define the extended instrument, target and control matrices

$$
\tilde{a}=\left(\begin{array}{c}
a \\
0 \\
0
\end{array}\right), \tilde{b}=\left(\begin{array}{l}
b \\
0 \\
0
\end{array}\right), \tilde{\kappa}=\left(\begin{array}{c}
\kappa_{1} \\
\kappa_{2} \\
\kappa_{3}
\end{array}\right),
$$

and formulate the general result for model (1).

Theorem 8 If $(i) x_{t}$ is a VAR(k) process given by (1) and (ii) we apply the recursively defined control rule

$$
x_{t}^{c t r}=x_{t}^{n e w}+\bar{a} \kappa_{1}^{\prime}\left(x_{t}^{n e w}-\gamma t\right)+\bar{a}\left(\sum_{i=1}^{k-1} \kappa_{i+1}^{\prime}\left(x_{t-i}^{c t r}-\gamma(t-i)\right)-\kappa_{0}\right),
$$


at all time points, and (iii) the new process is defined by the equations

$$
x_{t+1}^{n e w}=\left(I_{p}+\alpha \beta^{\prime}\right) x_{t}^{c t r}-\alpha \rho^{\prime} t-\alpha \mu+\sum_{i=1}^{k-1} \Gamma_{i}\left(\Delta x_{t+1-i}^{c t r}-\gamma\right)+\varepsilon_{t+1},
$$

then the stacked process $\left(x_{t}^{\text {new }}, x_{t-1}^{c t r}, \ldots, x_{t-k+1}^{c t r \prime}\right)^{\prime}$ is given by a VAR(1) model.

The stacked process is an I(1) process with $r+m$ cointegrating relations if and only if

$$
\left|\operatorname{eig}\left(\begin{array}{cc}
I_{r}+\tilde{\beta}^{\prime} \tilde{\alpha} & \left(I_{r}+\tilde{\beta}^{\prime} \tilde{\alpha}\right) \tilde{\beta}^{\prime} \tilde{a}\left(\tilde{a}^{\prime} \tilde{a}\right)^{-1} \\
\tilde{\kappa}^{\prime} \tilde{\alpha} & I_{m}+\tilde{\kappa}^{\prime}\left(I_{p}+\tilde{\alpha} \tilde{\beta}^{\prime}\right) \tilde{a}\left(\tilde{a}^{\prime} \tilde{a}\right)^{-1}
\end{array}\right)\right|<1 .
$$

In this case

$$
\left|\kappa^{\prime} C a\right| \neq 0
$$

and $\beta^{\prime} x_{t}^{n e w}-\rho^{\prime} t-\mu$ and $\kappa^{\prime}\left(x_{t}^{n e w}-\gamma t\right)-\kappa_{0}$ are stationary with mean zero. Here $\left(\kappa=\sum_{i=1}^{k} \kappa_{i}\right)$. The stacked process has a long-run impact matrix given by

$$
\left(\begin{array}{c}
I_{p} \\
I_{p} \\
\vdots \\
I_{p}
\end{array}\right)\left(C-C a\left(\kappa^{\prime} C a\right)^{-1} \kappa^{\prime} C\right)\left(\begin{array}{c}
I_{p} \\
-\Gamma_{1}^{\prime} \\
\vdots \\
-\Gamma_{k-1}^{\prime}
\end{array}\right)^{\prime}
$$

If $\tilde{\kappa}^{\prime} \tilde{\alpha}=0$, or equivalently

$$
\alpha^{\prime} \kappa_{1}=0, \tilde{\kappa}^{\prime}=\kappa_{1}^{\prime}\left(I_{p},-\Gamma_{1}, \ldots,-\Gamma_{k-1}\right),
$$

then $\kappa_{1}^{\prime} x_{t}^{\text {new }}+\sum_{i=2}^{k-1} \kappa_{i}^{\prime} x_{t-i+1}^{c t r}$ is a VAR(1) with coefficient matrix $I_{m}+\kappa_{1}^{\prime} \bar{a}$. Furthermore, if

$$
I_{m}+\kappa_{1}^{\prime} \bar{a}=0
$$

then $\kappa_{1}^{\prime} x_{t}^{n e w}+\sum_{i=2}^{k-1} \kappa_{i}^{\prime} x_{t-i+1}^{c t r}$ is white noise around its mean.

Proof. For notational simplicity we let $k=3$ and assume without loss of generality that $\gamma=0$, and hence $\rho=0$. The stacked process is given by the equations

$$
\Delta \tilde{x}_{t}=\tilde{\alpha}\left(\tilde{\beta}^{\prime} \tilde{x}_{t-1}-\tilde{\mu}\right)+\tilde{\varepsilon}_{t} .
$$

We now apply Theorem 7 to the stacked process and the control rule $\tilde{\kappa}$ at all time points and obtain from (16) and (17) the equations

$$
\tilde{x}_{t}^{c t r}=\tilde{x}_{t}^{\text {new }}+\tilde{a}\left(\tilde{a}^{\prime} \tilde{a}\right)^{-1}\left(\tilde{\kappa}^{\prime} \tilde{x}_{t}^{\text {new }}-\kappa_{0}\right)
$$


and

$$
\tilde{x}_{t+1}^{n e w}=\left(I_{3 p}+\tilde{\alpha} \tilde{\beta}^{\prime}\right) \tilde{x}_{t}^{c t r}-\tilde{\alpha} \tilde{\mu}+\tilde{\varepsilon}_{t+1} .
$$

From (36) we find for $\tilde{x}_{t}^{c t r}=\left(\tilde{x}_{1 t}^{c t r \prime}, \tilde{x}_{2 t}^{c t r \prime}, \tilde{x}_{3 t}^{c t r \prime}\right)^{\prime}$, and similarly for $\tilde{x}_{t}^{\text {new }}$, the equations

$$
\begin{aligned}
& \tilde{x}_{1 t}^{c t r}=\left(I_{p}+\bar{a} \kappa_{1}^{\prime}\right) \tilde{x}_{1 t}^{\text {new }}+\bar{a} \kappa_{2}^{\prime} \tilde{x}_{2 t}^{\text {new }}+\bar{a} \kappa_{3}^{\prime} \tilde{x}_{3 t}^{\text {new }}-\bar{a} \kappa_{0}, \\
& \tilde{x}_{2 t}^{c t r}=\tilde{x}_{2 t}^{\text {new }}, \\
& \tilde{x}_{3 t}^{c t r}=\tilde{x}_{3 t}^{\text {new }}
\end{aligned}
$$

and from (37) we get

$$
\begin{aligned}
& \tilde{x}_{1 . t+1}^{\text {new }}=\left(I_{p}+\alpha \beta^{\prime}+\Gamma_{1}\right) \tilde{x}_{1 t}^{c t r}-\left(\Gamma_{1}-\Gamma_{2}\right) \tilde{x}_{2 t}^{c t r}-\Gamma_{2} \tilde{x}_{3 t}^{c t r}-\alpha \mu+\varepsilon_{t+1}, \\
& \tilde{x}_{2 . t+1}^{\text {new }}=\tilde{x}_{1 t}^{c t r} \\
& \tilde{x}_{3 . t+1}^{\text {new }}=\tilde{x}_{2 t}^{c t r} .
\end{aligned}
$$

We find that

$$
\tilde{x}_{2 . t+1}^{c t r}=\tilde{x}_{2 . t+1}^{n e w}=\tilde{x}_{1 t}^{c t r}
$$

and

$$
\tilde{x}_{3 . t+1}^{c t r}=\tilde{x}_{3 . t+1}^{n e w}=\tilde{x}_{2 t}^{c t r}=\tilde{x}_{1 . t-1}^{c t r}
$$

so that for $x_{t}^{c t r}=\tilde{x}_{1 t}^{c t r}$ and $x_{t}^{\text {new }}=\tilde{x}_{1 t}^{\text {new }}$, we get

$$
\tilde{x}_{t}^{c t r}=\left(\begin{array}{c}
x_{t}^{c t r} \\
x_{t-1}^{c t r} \\
x_{t-2}^{c t r}
\end{array}\right), \tilde{x}_{t}^{\text {new }}=\left(\begin{array}{c}
x_{t}^{\text {new }} \\
x_{t-1}^{c t r} \\
x_{t-2}^{c t r}
\end{array}\right) .
$$

Substituting (36) into (37) we see that $\tilde{x}_{t+1}^{\text {new }}$ satisfies the VAR(1) model

$$
\tilde{x}_{t+1}^{\text {new }}=A \tilde{x}_{t}^{\text {new }}-\left(I_{3 p}+\tilde{\alpha} \tilde{\beta}^{\prime}\right) \tilde{a}\left(\tilde{a}^{\prime} \tilde{a}\right)^{-1} \kappa_{0}-\tilde{\alpha} \tilde{\mu}+\tilde{\varepsilon}_{t+1},
$$

where $A$ is given by

$$
A=\left(\begin{array}{ccc}
B\left(I_{p}+\bar{a} \kappa_{1}^{\prime}\right) & B \bar{a} \kappa_{2}^{\prime}-\Gamma_{1}+\Gamma_{2} & B \bar{a} \kappa_{3}^{\prime}-\Gamma_{2} \\
I_{p}+\bar{a} \kappa_{1}^{\prime} & \bar{a} \kappa_{2}^{\prime} & \bar{a} \kappa_{3}^{\prime} \\
0 & I_{p} & 0
\end{array}\right)
$$

with $B=I_{p}+\alpha \beta^{\prime}+\Gamma_{1}$. The first equation in (40) defines $x_{t+1}^{\text {new }}$ in terms of $x_{t}^{\text {new }}$ and the lagged "controlled" values that were valid in previous periods. The next set of equations defines the controlled values based on the intervention rule (38). Note that $\tilde{x}_{t}^{\text {new }}$ is not a VAR process in companion form because of the 
second set of equations. Hence the first component, $x_{t}^{\text {new }}$, need not be a VAR process.

From Theorem 7 we find, under assumption (31), that the processes

$$
\begin{aligned}
& \tilde{\beta}^{\prime} \tilde{x}_{t}^{\text {new }}=\left(x_{t}^{\text {new' }} \beta, x_{t}^{\text {new }}-x_{t-1}^{c t r \prime}, x_{t-1}^{c t r \prime}-x_{t-2}^{c t r \prime}\right)^{\prime} \\
& \tilde{\kappa}^{\prime} \tilde{x}_{t}^{\text {new }}=\kappa_{1}^{\prime} x_{t}^{\text {new }}+\kappa_{2}^{\prime} x_{t-1}^{c t r}+\kappa_{3}^{\prime} x_{t-2}^{c t r}
\end{aligned}
$$

are stationary around $\tilde{\mu}$ and $\kappa_{0}$ respectively. This shows that $\beta^{\prime} x_{t}^{n e w}-\mu, x_{t}^{\text {new }}-$ $x_{t-1}^{c t r}$, and $x_{t-1}^{c t r}-x_{t-2}^{c t r}$ are stationary with mean zero. From

$$
\kappa_{1}^{\prime} x_{t}^{\text {new }}+\kappa_{2}^{\prime} x_{t-1}^{c t r}+\kappa_{3}^{\prime} x_{t-2}^{c t r}=\kappa^{\prime} x_{t}^{\text {new }}-\kappa_{2}^{\prime}\left(x_{t}^{\text {new }}-x_{t-1}^{c t r}\right)-\kappa_{3}^{\prime}\left(x_{t}^{\text {new }}-x_{t-2}^{c t r}\right)
$$

it follows that $\kappa^{\prime} x_{t}^{\text {new }}-\kappa_{0}$ is also stationary with mean zero.

Finally we notice that

$$
\tilde{\kappa}^{\prime} \tilde{C} \tilde{a}=\left(\kappa_{1}^{\prime}, \kappa_{2}^{\prime}, \kappa_{3}^{\prime}\right)\left(\begin{array}{c}
I_{p} \\
I_{p} \\
I_{p}
\end{array}\right) C\left(\begin{array}{c}
I_{p} \\
-\Gamma_{1}^{\prime} \\
-\Gamma_{2}^{\prime}
\end{array}\right)^{\prime}\left(\begin{array}{l}
a \\
0 \\
0
\end{array}\right)=\kappa^{\prime} C a,
$$

which proves (32), and shows that (33) is a consequence of (21). The condition $\tilde{\alpha}^{\prime} \tilde{\kappa}=0$, becomes

$$
\alpha^{\prime} \kappa_{1}=0, \Gamma_{1}^{\prime} \kappa_{1}+\kappa_{2}=\Gamma_{2}^{\prime} \kappa_{1}+\kappa_{3}=0 .
$$

\section{A.3 Controlling a stationary variable}

We finally give a result on the control of a stationary variable.

Theorem 9 If $x_{t}$ is given by the model

$$
\Delta x_{t}=\alpha\left(\beta^{\prime} x_{t-1}-\mu\right)+\varepsilon_{t}
$$

and we apply the control rule

$$
x_{t}^{c t r}=x_{t}+\bar{a}\left(\phi^{\prime}\left(\beta^{\prime} x_{t}-\mu\right)-\kappa_{0}\right),
$$

at all time points, then the new process $x_{t}^{\text {new }}$ is given by a VAR(1) model which is $I(1)$ with cointegrating space $\operatorname{sp}(\beta)$, and adjustment space $\operatorname{sp}\left(\alpha+\left(\alpha \beta^{\prime}+I_{p}\right) \bar{a} \phi^{\prime}\right)$, if and only if

$$
\left|e i g\left(I_{r}+\beta^{\prime} \alpha\right)\left(I_{r}+\beta^{\prime} \bar{a} \phi^{\prime}\right)\right|<1 .
$$

In this case $\phi^{\prime}\left(\beta^{\prime} x_{t}^{\text {new }}-\mu\right)-\kappa_{0}$ is stationary with mean

$$
-\left(I_{r}+\phi^{\prime}\left(I_{r}+\left(\beta^{\prime} \alpha\right)^{-1}\right) \beta^{\prime} \bar{a}\right)^{-1} \kappa_{0} .
$$


If $b^{\prime} x_{t}$ is stationary, $b^{*}$ is the desired target value, and $b^{\prime} a=0$, then the control rule

$$
x_{t}^{c t r}=x_{t}+\bar{a}\left(b^{\prime} x_{t}-b^{*}-\Theta^{-1}\left(b^{*}-b^{\prime} \alpha\left(\beta^{\prime} \alpha\right)^{-1} \mu\right)\right),
$$

makes $b^{\prime} x_{t}$ stationary around $b^{*}$, provided

$$
\Theta=b^{\prime} \alpha\left(\beta^{\prime} \alpha\right)^{-1}\left(\beta^{\prime} \alpha+I_{r}\right)\left(\beta^{\prime} \alpha\right)^{-1} \beta^{\prime} \bar{a}=-\left.b^{\prime} A(z)^{-1} \bar{a}\right|_{z=1}
$$

has full rank, where $A(z)$ is the characteristic polynomial of the process.

Condition (43) is roughly the same as the condition $\left|b^{\prime} C a\right| \neq 0$, in the sense that they both relate to the leading term in the expansion of $A(z)^{-1}$, since if $\left|b^{\prime} C a\right| \neq 0$, then

$$
b^{\prime} C a=\lim _{z \rightarrow 1}(1-z) b^{\prime} A(z)^{-1} a .
$$

Proof. We find as before the equations

$$
\Delta x_{t+1}^{n e w}=\left(\alpha+\left(I_{p}+\alpha \beta^{\prime}\right) \bar{a} \phi^{\prime}\right)\left(\beta^{\prime} x_{t}^{n e w}-\mu\right)-\left(I_{p}+\alpha \beta^{\prime}\right) \bar{a} \kappa_{0}+\varepsilon_{t+1} .
$$

The condition for the process to be $I(1)$ is

$$
\left|e i g\left(I_{r}+\beta^{\prime}\left(\alpha+\left(I_{p}+\alpha \beta^{\prime}\right) \bar{a} \phi^{\prime}\right)\right)\right|<1,
$$

which is equivalent to (41). Multiplying (44) by $\beta^{\prime}$ we find, since $E\left(\beta^{\prime} \Delta x_{t}^{\text {new }}\right)=$ 0 , that

$$
0=\beta^{\prime}\left(\alpha+\left(I_{p}+\alpha \beta^{\prime}\right) \bar{a} \phi^{\prime}\right) E\left(\beta^{\prime} x_{t}^{n e w}-\mu\right)-\left(I_{r}+\beta^{\prime} \alpha\right) \beta^{\prime} \bar{a} \kappa_{0} .
$$

The coefficient matrix to $E\left(\beta^{\prime} x_{t}^{\text {new }}\right)$ is full rank by assumption (41). Hence, with $\psi=\left(I_{r}+\left(\beta^{\prime} \alpha\right)^{-1}\right) \beta^{\prime} \bar{a}$ we find

$$
\phi^{\prime} E\left(\beta^{\prime} x_{t}^{\text {new }}-\mu\right)=\phi^{\prime}\left(I_{r}+\phi^{\prime} \psi\right)^{-1} \psi \kappa_{0}=\phi^{\prime} \psi\left(I_{r}+\phi^{\prime} \psi\right)^{-1} \kappa_{0},
$$

which shows (42).

If $b^{\prime} x_{t}$ is stationary, then $b=\beta \phi$. We can choose $\phi=\left(\alpha^{\prime} \beta\right)^{-1} \alpha^{\prime} b$ and, using (42), it follows that

$$
E\left(b^{\prime} x_{t}^{\text {new }}\right)=E\left(\phi^{\prime} \beta^{\prime} x_{t}^{\text {new }}\right)=\phi^{\prime} \mu+\Theta\left(I_{r}+\Theta\right)^{-1} \kappa_{0}=b^{*},
$$

which has the solution

$$
\kappa_{0}=\left(I_{r}+\Theta^{-1}\right)\left(b^{*}-\phi^{\prime} \mu\right) .
$$

Hence, $b^{\prime} x_{t}^{\text {new }}$ has mean $b^{*}$, when $\Theta$ has full rank.

Condition (43) concerns the matrix $\Theta$ which we simplify using the relation $b^{\prime} \alpha\left(\beta^{\prime} \alpha\right)^{-1} \beta^{\prime} \bar{a}=b^{\prime} \bar{a}=0$ 


$$
\begin{aligned}
\Theta & =b^{\prime} \alpha\left(\beta^{\prime} \alpha\right)^{-1}\left(\beta^{\prime} \alpha+I_{r}\right)\left(\beta^{\prime} \alpha\right)^{-1} \beta^{\prime} \bar{a} \\
& =b^{\prime} \bar{a}+b^{\prime} \alpha\left(\beta^{\prime} \alpha\right)^{-2} \beta^{\prime} \bar{a}=b^{\prime} \alpha\left(\beta^{\prime} \alpha\right)^{-2} \beta^{\prime} \bar{a} .
\end{aligned}
$$

We finally find the characteristic polynomial and its inverse

$$
\begin{aligned}
& A(z)=(1-z) I_{p}-\alpha \beta^{\prime} z, \\
& A(z)^{-1}=C \frac{1}{1-z}+\alpha\left(\beta^{\prime} \alpha\right)^{-1} \sum_{i=0}^{\infty}\left(I_{r}+\beta^{\prime} \alpha\right)^{i} \beta^{\prime} z^{i}, z \neq 1,
\end{aligned}
$$

and for $b=\beta \phi$, we have

$$
\left.b^{\prime} A(z)^{-1} a\right|_{z=1}=\left.b^{\prime} \alpha\left(\beta^{\prime} \alpha\right)^{-1} \sum_{i=0}^{\infty}\left(I_{r}+\beta^{\prime} \alpha\right)^{i} \beta^{\prime} a z^{i}\right|_{z=1}=-b^{\prime} \alpha\left(\beta^{\prime} \alpha\right)^{-2} \beta^{\prime} a .
$$




\section{B Appendix: The data.}
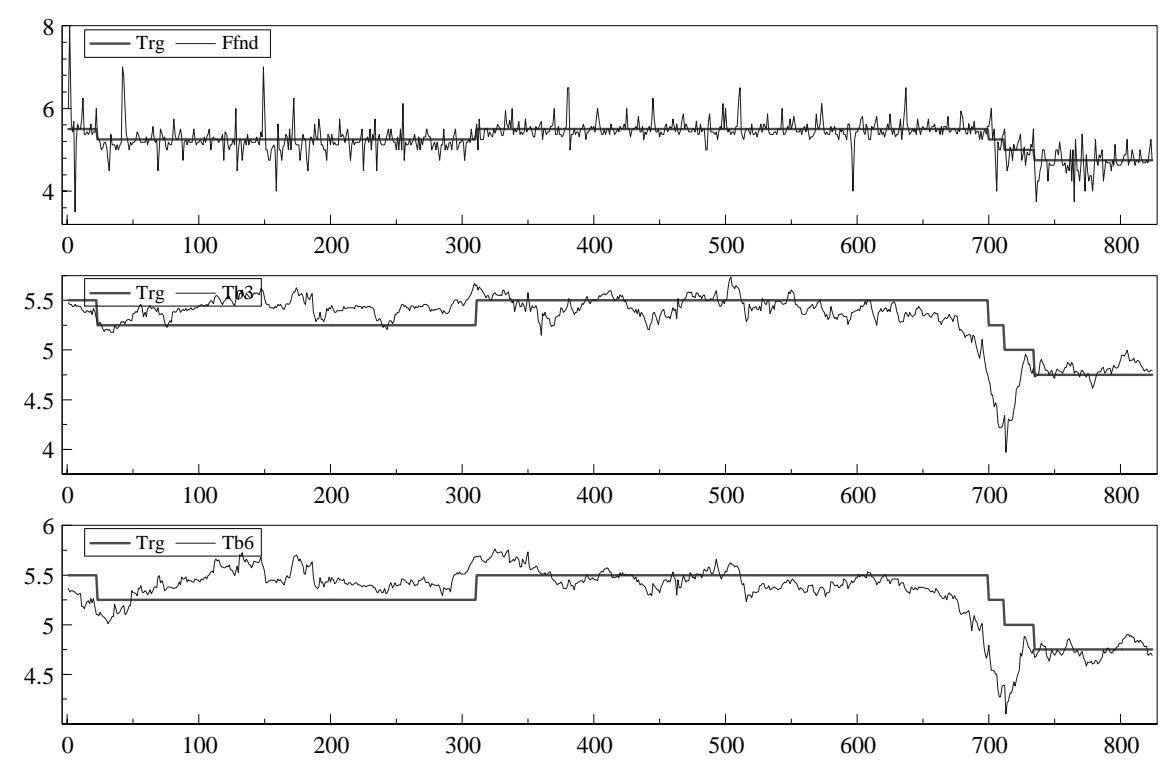

Figure 8: Daily observations of the federal target rate and the federal funds rate (panel a), the 3 months treasury bill rate and the federal target rate (panel b), and the 6 months treasury bill rate and the federal target rate (panel c) over the period 1996.01.02 to 1999.03.26. The plots are mean adjusted. 

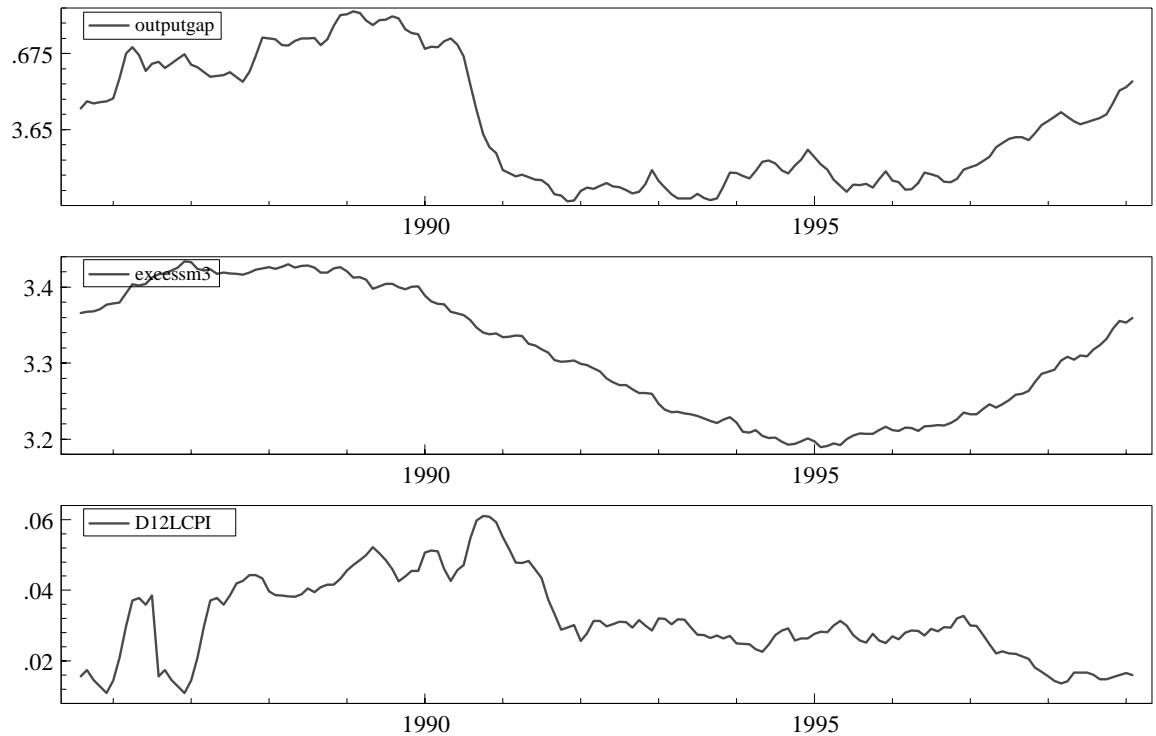

Figure 9: The graphs of monthly observations of the deviation of real GDP from a linear trend (panel a), deviations of real M3 from a linear trend (panel b), and the yearly CPI inflation rates (panel c). 

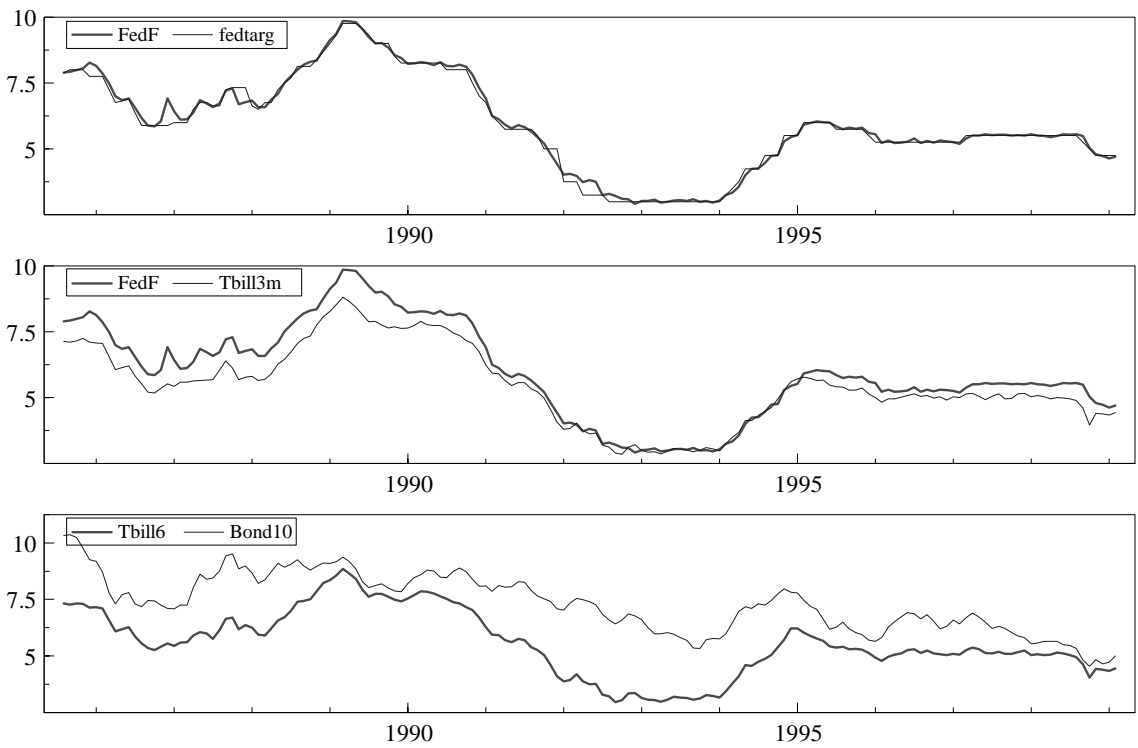

Figure 10: The graphs of monthly observations of the federal reserve rate and the federal target rate (panel a), the 3 months treasury bill rate and the target rate (panel b), and finally the 6 months treasury bill rate and the 10 years government bond rate (panel c). 